\title{
Numerical Study of Inter-yarn Friction on the Failure of Fabrics upon Ballistic Impacts
}

DOI:

10.1016/..matdes.2016.11.013

\section{Document Version}

Accepted author manuscript

Link to publication record in Manchester Research Explorer

\section{Citation for published version (APA):}

Chu, Y., Min, S., \& Chen, X. (2016). Numerical Study of Inter-yarn Friction on the Failure of Fabrics upon Ballistic Impacts. Materials \& Design. https://doi.org/10.1016/j.matdes.2016.11.013

\section{Published in:}

Materials \& Design

\section{Citing this paper}

Please note that where the full-text provided on Manchester Research Explorer is the Author Accepted Manuscript or Proof version this may differ from the final Published version. If citing, it is advised that you check and use the publisher's definitive version.

\section{General rights}

Copyright and moral rights for the publications made accessible in the Research Explorer are retained by the authors and/or other copyright owners and it is a condition of accessing publications that users recognise and abide by the legal requirements associated with these rights.

\section{Takedown policy}

If you believe that this document breaches copyright please refer to the University of Manchester's Takedown Procedures [http://man.ac.uk/04Y6Bo] or contact uml.scholarlycommunications@manchester.ac.uk providing relevant details, so we can investigate your claim.

\section{OPEN ACCESS}




\section{Accepted Manuscript}

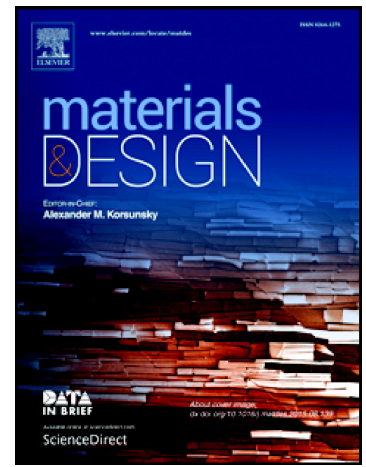

Numerical study of inter-yarn friction on the failure of fabrics upon ballistic impacts

Yanyan Chu, Shengnan Min, Xiaogang Chen

PII:

S0264-1275(16)31401-0

DOI: doi: $10.1016 /$ j.matdes.2016.11.013

Reference:

JMADE 2449

To appear in:

Materials \& Design

Received date:

9 August 2016

Revised date:

28 October 2016

Accepted date:

3 November 2016

Please cite this article as: Yanyan Chu, Shengnan Min, Xiaogang Chen , Numerical study of inter-yarn friction on the failure of fabrics upon ballistic impacts. The address for the corresponding author was captured as affiliation for all authors. Please check if appropriate. Jmade(2016), doi: 10.1016/j.matdes.2016.11.013

This is a PDF file of an unedited manuscript that has been accepted for publication. As a service to our customers we are providing this early version of the manuscript. The manuscript will undergo copyediting, typesetting, and review of the resulting proof before it is published in its final form. Please note that during the production process errors may be discovered which could affect the content, and all legal disclaimers that apply to the journal pertain. 


\title{
Numerical Study of Inter-yarn Friction on the Failure of Fabrics
}

\section{upon Ballistic Impacts}

\author{
Yanyan Chu ${ }^{1,3,4}$ Shengnan Min $^{2,3} \quad$ Xiaogang Chen ${ }^{1,3}$ \\ 1. Zhongyuan University of Technology, Zhengzhou, Henan, 450007, China \\ 2. Beijing Institute of Fashion Technology, Beijing, 100029, China
}

3. The University of Manchester, Manchester, M13 9PL, UK

4. Collaborative Innovation Centre of Textile and Garment Industry, Zhengzhou, Henan, 450007, China

This paper investigates the influence of inter-yarn friction in fabrics on the ballistic performances of the target including failure. Finite element (FE) method was adopted for the study, where FE models were established for two types of fabrics based on the yarn properties of Twaron ${ }^{\circledR}$ and Dyneema ${ }^{\circledR}$, respectively. Numerical analyses on the responses of the primary and secondary yarns in the fabrics subjected to ballistic impact were carried out based on these fabric models. The results show that larger inter-yarn friction leads to less slippage of primary yarns at impact centre. In addition, higher inter-yarn friction make more involvement of the secondary yarns join in loading the impact energy, so as to alleviate the loads in primary yarns and prolong the failure of primary yarns. However, if the inter-yarn friction is too high, beyond coefficient of static friction (CSF) of 0.8 and coefficient of kinetic friction (CKF) of 0.75 , the action would be counterproductive. The reason is that the stress at those inter-yarn friction levels would be more concentrated on the primary yarns, resulting in an earlier failure of a fabric.

Keywords: Ballistic impact, Inter-yarn friction, fabric, Finite element, Primary yarns, Secondary yarns.

\section{Introduction}

Fibres with high strength and high stiffness are favourable materials for ballistic protective applications. According to their chemical structures, those fibres are generally classified into three groups, including aramid fibres such as $\operatorname{Kevlar}^{\circledR}$ (by DuPont) and Twaron ${ }^{\circledR}$ (by Teijin), ultra-heavy molecular weight polyethylene (UHMWPE) fibres such as Dyneema ${ }^{\circledR}$ (by DSM) and Spectra ${ }^{\circledR}$ (by Honeywell) and Poly-p-phenylene benzobisoxazole (PBO) fibres such as Zylon ${ }^{\circledR}$ (by Toyobo). These fibres can be woven into a fabric structure providing the strength and toughness that substantially surpasses those of individual strands ${ }^{[1]}$. The impact resistance of the fabrics is generally attributed to various factors, 
including weaving architecture, crimp, thread density, yarn linear density, crossover number, sample size and so on ${ }^{[2]}$. Among these factors, inter-yarn friction is considered to be vital of importance. Magno et al. ${ }^{[3]}$ established a microscopic model for a fabric and investigate the uniaxial extension of the fabric without consider the interaction between warp yarn and weft yarns, where Boubaker et al. ${ }^{[4]}$ considered inter-yarn friction in their model and found that consideration of the yarn-on-yarn friction leads to a stiffer response of fabric.

Numerical method is one of the commonly used methods for ballistic investigation ${ }^{[5-14]}$. The advantages of this method are obvious; for example, time saved, labour saved and material saved, and especially precise control of fabric structure and boundary condition. In the numerical study, the effects of inter-yarn friction are usually theoretically investigated by $\mathrm{FE}$ (Finite Element) simulations, where different levels of coefficients of friction are used as the input information indicating various levels of inter-yarn friction. With this method, Zeng et al. ${ }^{[7]}$, Gogineni et al. ${ }^{[8]}$, Zhou et al. ${ }^{[10]}$ and Sun et al. ${ }^{[11]}$ in their simulations observed that the energy absorption increases with the coefficient of friction in certain range, whereas the energy absorption begins to decrease at much higher frictional levels. Rao et al. ${ }^{[13]}$ and Parsons et al. ${ }^{[14]}$ found that the ballistic limit is also affected by inter-yarn friction. Ballistic limit designates a velocity at which a projectile completely perforates specific armour when hitting at a specified angle of obliquity. Their results showed that the higher inter-yarn friction, the higher ballistic limit would be. Duan et al. ${ }^{[5,}$ ${ }^{6]}$ and Nilakantan et al. ${ }^{[9]}$ have investigated the influence of inter-yarn friction under different boundary conditions. They found that the effects of inter-yarn friction relates to the clamp conditions. Minh et al. ${ }^{[12]}$ attempted to reveal the individual effect of inter-yarn friction and projectile-fabric friction on the ballistic performance of a three dimensional (3D) interlock fabric target. Their work indicated that the inter-yarn friction assists in maintaining the structural integrity of the whole fabric during the impact event. 
The mechanism of inter-yarn friction during ballistic impact has been also investigated by experimental work ${ }^{[15-19]}$. Briscoe and Motamedi ${ }^{[15]}$ as well as Hearle et al. ${ }^{[16]}$ applied treatments to ballistic fabrics and obtained several levels of inter-yarn friction. Their experimental work demonstrated that increasing inter-yarn friction to some degree would be beneficial for improving ballistic performance of fabrics. Briscoe and Motamedi ${ }^{[15]}$ ascribed the improved ballistic performance to the higher transverse stiffness of the fabric at higher inter-yarn friction. In addition, some researchers tried to investigate the ballistic fabrics treated with STF (shear thickening fluid) and found the increase of inter-yarn friction after STF treatment being one of the reasons for the improved ballistic performance. Other than surface treatment for different levels of inter-yarn friction, Sun $^{[17,18]}$ and Zhou ${ }^{[19]}$ also tried to differentiates the inter-yarn friction by utilising different textile woven structure. Contrary to their expectations, no significant difference in energy absorption was found among the fabrics with extra yarn gripping and the plain fabric, although the levels of inter-yarn friction achieved were different.

Although, previous researchers with these two methods provided some insights into the effects of inter-yarn friction during the ballistic impact, there are still some gaps between different researcher's understandings. The role of inter-yarn friction needs to be further dug out. In such, the effects of inter-yarn friction on a single-layer fabric subjected to ballistic impact will be theoretically analysed through FE simulation based on the model established. The effects of inter-yarn friction on ballistic performance will be comprehensively elucidated from the perspectives of primary yarns, and secondary yarns. Moreover, the role of primary yarns and secondary yarns and the failure mechanism will be discussed. It is anticipated that through FE analyses, the effects of inter-yarn friction will be uncovered and the direction for improving the ballistic performance through increasing inter-yarn friction will be acquired.

\section{Experimental work}


The experimental work here is to valid the simulation results. It is conducted on a ballistic range similarly to that described in reference[20].The fabric used for experimental analysis is a single-layer plain Twaron ${ }^{\circledR}$ fabric. It is constructed from yarns with the linear density of 93 tex. The warp and weft density are designed to be identical, 7.8 ends/cm. The areal density of the fabric is $153.61 \mathrm{~g} / \mathrm{cm}^{2}$.

\section{Modelling}

\subsection{Fabric architecture and projectile}

The fabric architecture is clearly a multi-scale: the macroscopic scale(the fabric), the mesoscopic scale( the fabric assembled of yarns) and the microscopic scale(the fabric composed of fibres) ${ }^{[21]}$. The macroscopic scale usually models the fabric as a membrane or shell and it cannot catch the yarn-yarn interaction. The microscopic scale is very difficult accounting for the number of fibres. Therefore, in present investigation the fabric is modelled at mesoscopic scale in ABAQUS, the software employed for FE modelling. The microscopic scale at yarn-level was proved being capable of capturing the behaviours of the fabric upon ballistic impact ${ }^{[14]}$. For the mesoscopic scale model, the yarns can be modelled as 3D continuum yarns or represented by representative volume element (RVE) ${ }^{[22]}$. The $3 \mathrm{D}$ continuum yarn model is chosen in present investigation for characterisation of the geometry of yarns and the inter-yarn friction. The fabric created is identical to that in the experimental test.

To create a 3D continuum yarn part in the ABAQUS/CAE, the cross-section and the wavelength of the yarn are the basic information. Figure 1 and 2 depict micro-images of the yarn cross-sections and the waviness of yarns in the fabric by using an optical microscope. Based on the micro-image in Figure 1, the yarn cross-section can be realistically represented by lenticular model. From Figure 2, the wave path can be considered as being constructed by two lenticular arcs. According to the actual fabric structure, shown in figure 3, the average width of the cross-section of the yarn in model is 
$1.134 \mathrm{~mm}$ and the average wavelength of the yarn is $2.556 \mathrm{~mm}$. The average thickness of the fabric is measured as $0.210 \mathrm{~mm}$ by using the vernier caliper. The geometry parameters for the generated yarn part and the fabric assembly are shown in Figure 4. The projectile is a steel cylinder with the diameter and height both being $5.5 \mathrm{~mm}$. The mass of it is $1.00 \mathrm{~g}$.

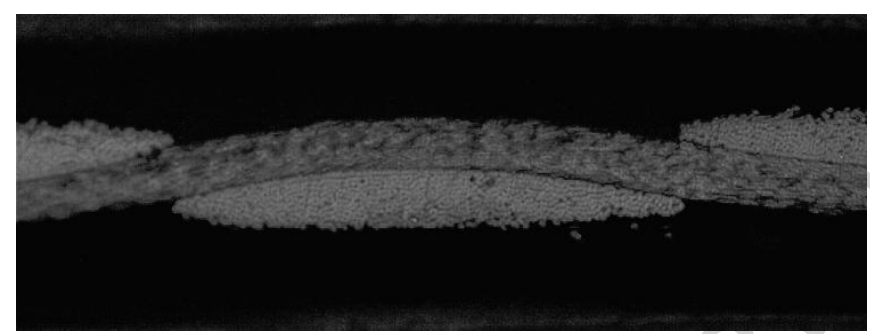

Figure 1The cross-section of the yarn in the fabric

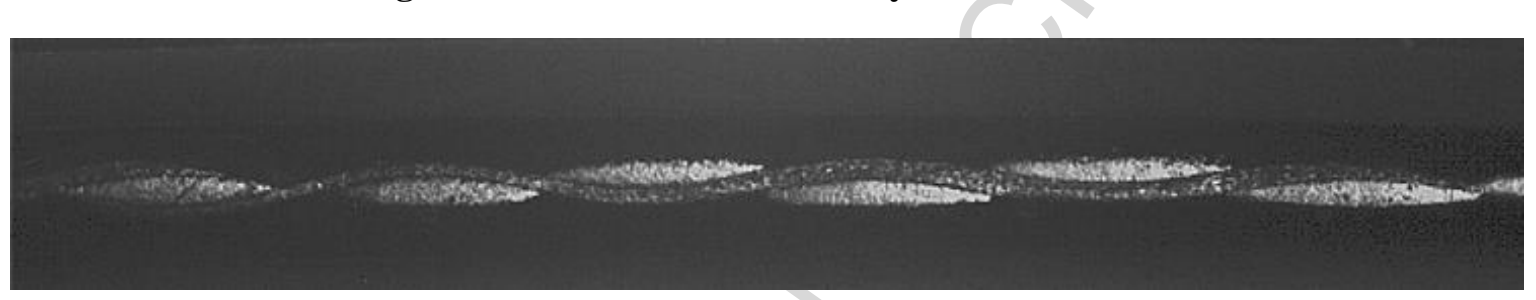

Figure 2 The crimp waviness of the yarn in the fabric

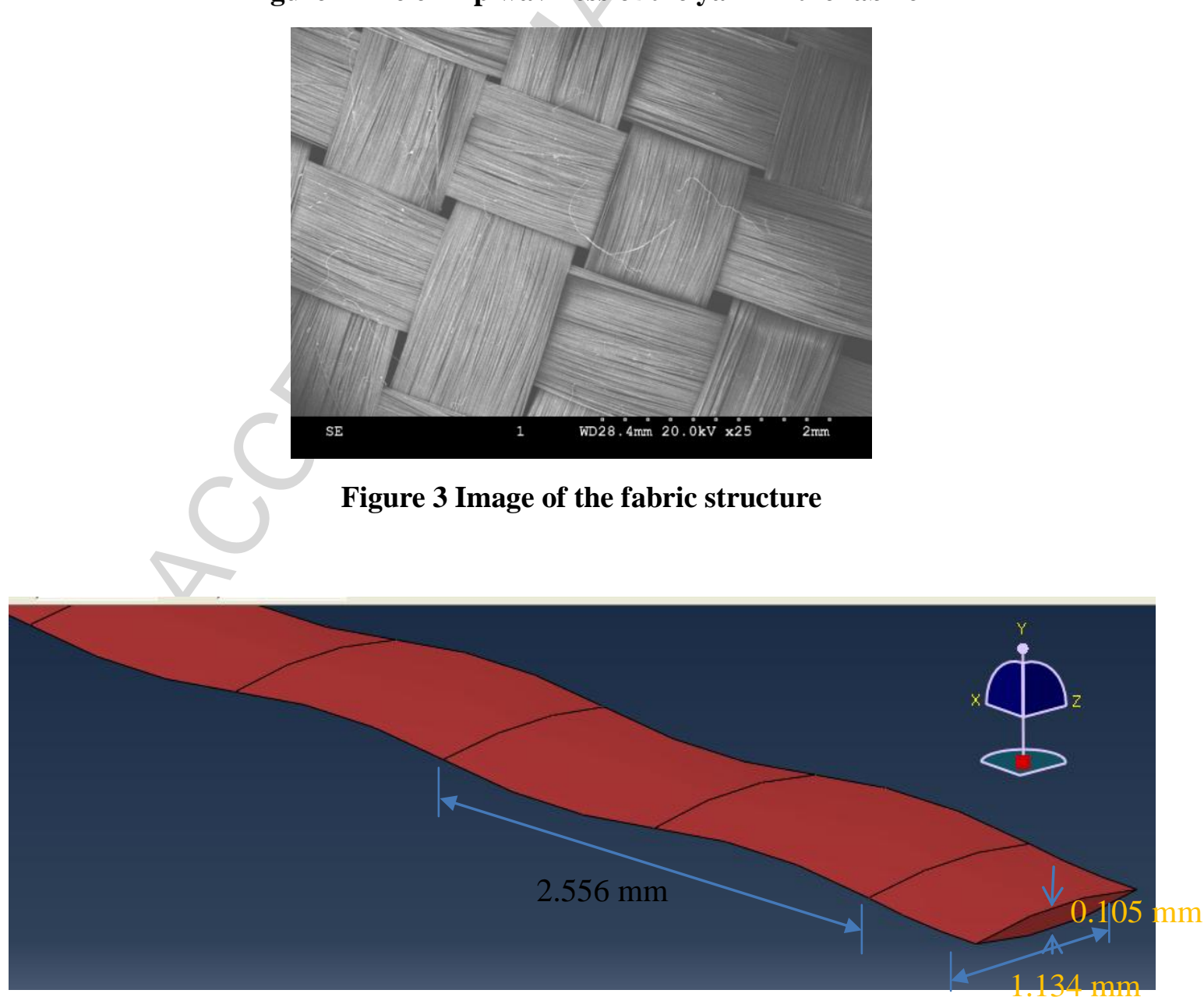


Figure 4 Yarn geometrical parameters in the model for TM and DYM fabric

Since the projectile-fabric assembly is symmetric, only a quarter of the fabric area is needed for the simulation, as shown in Figure 5(a) This would save up to $75 \%$ amount of the computation time. The fabric size in current model is the same as the actual size used for the ballistic impact test. It is circle and the radius of it is $7.5 \mathrm{~cm}$. The warp yarn is positioned along $\mathrm{X}$ direction and the weft yarn along $\mathrm{Z}$ direction in a three dimensional space. According to the nature of clamping employed in experimental tests, the fabric target is clamped around the edges, leaving a circular test field, as shown in Figure 5(b). Therefore, the circumference of the quarter fabric is fixed, and the remaining two sides are given symmetric boundary condition. The fabric is placed in the $X-Z$ plane, impacted by the projectile from the negative $\mathrm{Y}$ direction. The projectile is generated to have the same geometry parameters as that in the ballistic impact experiment. All the freedoms for the projectile movement are restricted but it is allowed to move along the negative direction of $\mathrm{Y}$ axis. The projectile/fabric contact is defined as surface to surface contact, and yarn/yarn contact is given a global contact algorithm. The inter-yarn friction is defined with a formulation of static-kinetic exponential decay. The yarn and the projectile are meshed by C3D8R elements, shown in Figure 6(a) and (b), meaning a solid element type of 8-node linear brick, reduced integration, hourglass control. The cross-section of the yarn is meshed with ten elements, which is determined from the computational accuracy of the model and mesh sensitivity ${ }^{[5-6]}$. The analysis used in this research is ABAQUS/Explicit. The time step is set when the projectile speed no longer change.

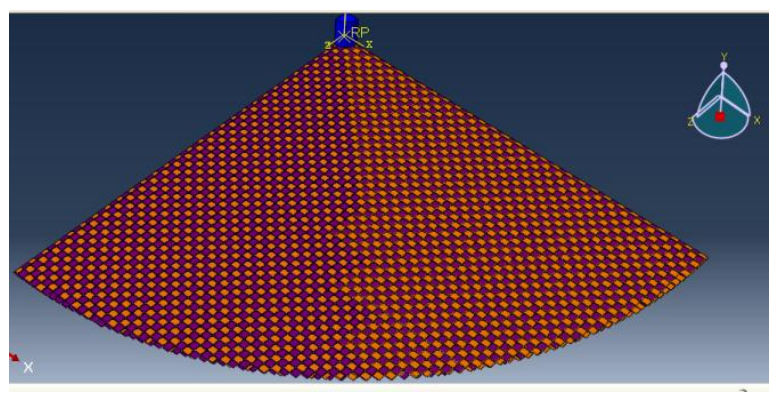

(a)

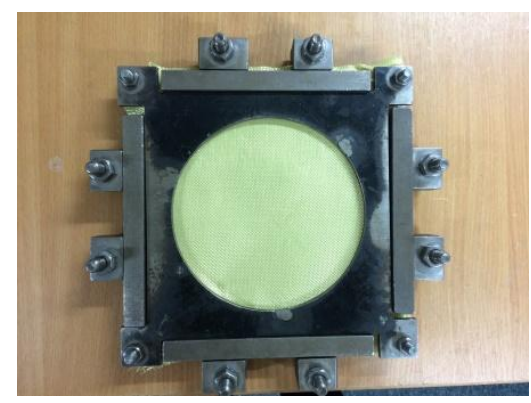

(b) 
Figure 5 The modelled (a)fabric assembly and (b) the nature of fabric boundary

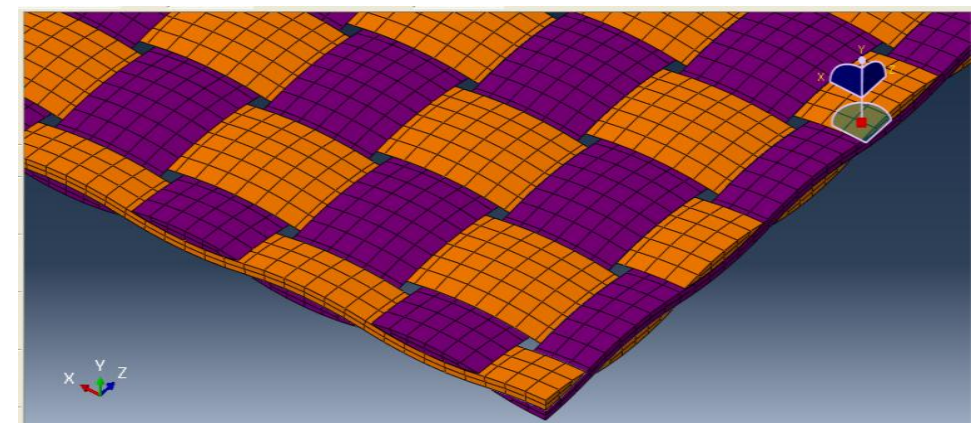

(a)

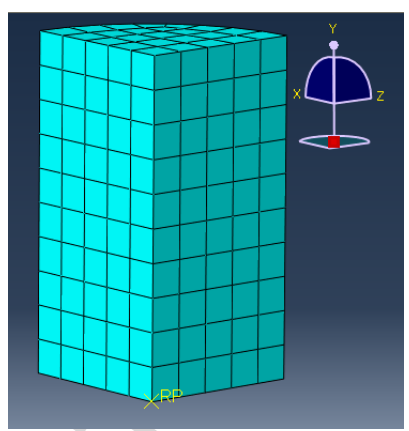

(b)

Figure 6 The mesh for (a)the fabric and (b)the projectile

\subsection{Validation of the model}

To validate the model, the material parameters configuration should be consistent with the real yarn properties. Based on previous investigations ${ }^{[7]}$, the Young's modulus of Twaron ${ }^{\circledR}$ yarns is $72 \mathrm{GPa}$ at the strain rate of $1000 \mathrm{~s}^{-1}$. The fracture strain and the yield stress are estimated as $4.28 \%$ and $2.9 \mathrm{GPa}$, respectively. The density of the Twaron ${ }^{\circledR}$ yarn is set as $1268 \mathrm{~kg} / \mathrm{m}^{3}$ according to packing density of fibres in yarns with a value of approximately 0.89. The Poisson's ratio of the yarn is set as $0.3^{[8]}$. The inter-yarn friction between Twaron ${ }^{\circledR}$ yarns are set to be 0.16 for coefficient of static friction and 0.15 for coefficient of kinetic friction base on Capstan test. The projectile is steel with the density of $7687 \mathrm{~g} / \mathrm{cm}^{3}$. Compared to the fabric, the projectile is much stiffer. As such, the projectile is defined as a rigid body, which means that it is not deformable in the whole process. The Poisson's ratio of it is set as $0.3^{[23]}$.

\subsubsection{Residual velocity}

Figure 7 compares the residual velocities from the FE simulation to those from the experimental test when the projectile impacts a single-layer Twaron ${ }^{\circledR}$ fabric. The residual velocity is the velocity at the moment when the projectile penetrates through the fabric. In Figure 7, the horizontal axis and the vertical axis represent the experimental residual velocity and the corresponding residual velocity from the FE simulation, respectively. 
From the equation of linear regression added to the scatter points, the correlation coefficient $\mathrm{R}^{2}$ is close to 1 , manifesting that the residual velocities from FE simulation are linearly related to those from ballistic test. From the equation displayed in Figure 7, the slope value is around 1, indicating that the difference between the residual velocities from FE and experiment is minimal. Thus, the results from the FE simulation model have a good consistency with the experimental results with respect to the residual velocity.

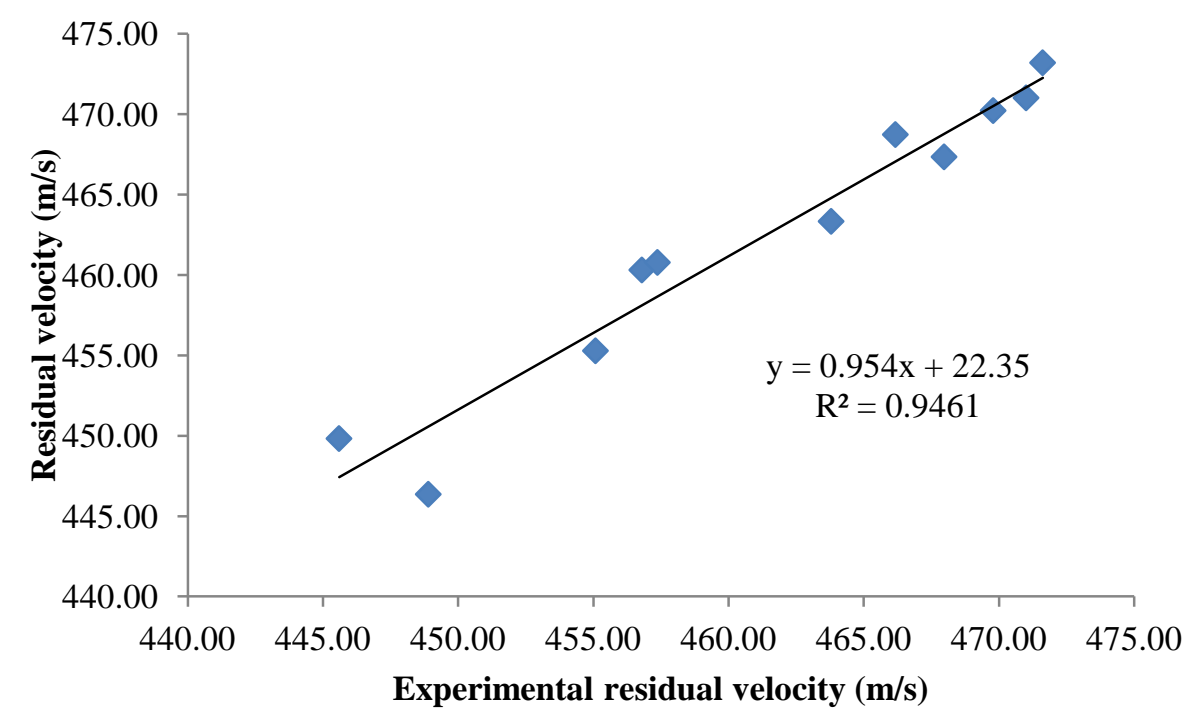

Figure 7 Comparison of residual velocity between experimental and FE model

\subsubsection{Transverse wave velocity}

Transverse wave propagation in the fabric is one of the essential characteristics of the ballistic behaviours. Figure 8 compares the transverse wave propagation in the fabric from FE simulation to that recorded from the high-speed camera. The resolution is configured as 250000 frame/second because higher resolution will lead to much smaller area taken into the visual field of camera. Consequently, the picture is recorded every $4 \mu \mathrm{s}$. From the FE simulation results, the transverse wave propagates to the 4.5 th yarn at $4 \mu \mathrm{s}$ counted from the impact centre and the 6.5 th yarn at $8 \mu \mathrm{s}$ and the 8.5 th at $12 \mu \mathrm{s}$. In order to clearly observe where the transverse wave propagates at a certain time on the images taken from the high-speed camera, the area involved is outlined by the red lines, as shown in Figure 8. The images are recorded in the case of the impact velocity of $473.21 \mathrm{~m} / \mathrm{s}$. These images 
show that at $4 \mu \mathrm{s}$, the transverse wave travels to approximately 3-3.5th yarn, and to 6th yarn at $8 \mu \mathrm{s}$ and to 8 th yarn at $12 \mu \mathrm{s}$, respectively. Based on above comparisons, the transverse wave was found to propagate almost at the same speed in the two methods. Therefore, the results from the FE model can capture the transverse wave propagation correctly.

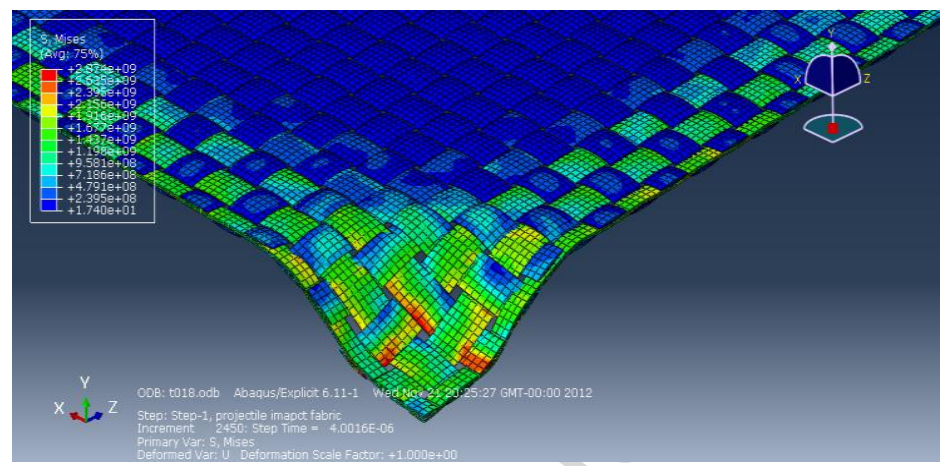

(a) $4 \mu \mathrm{s}$

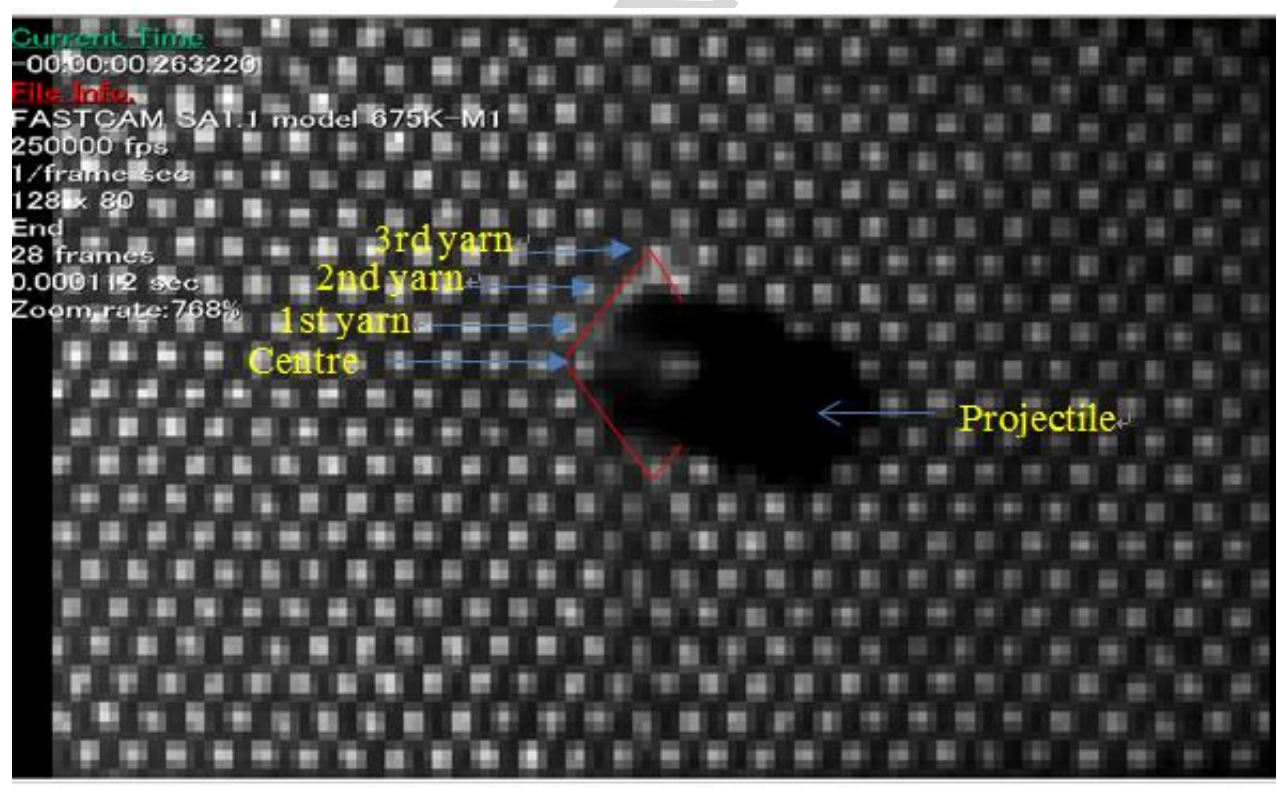

(a') $4 \mu \mathrm{s}$

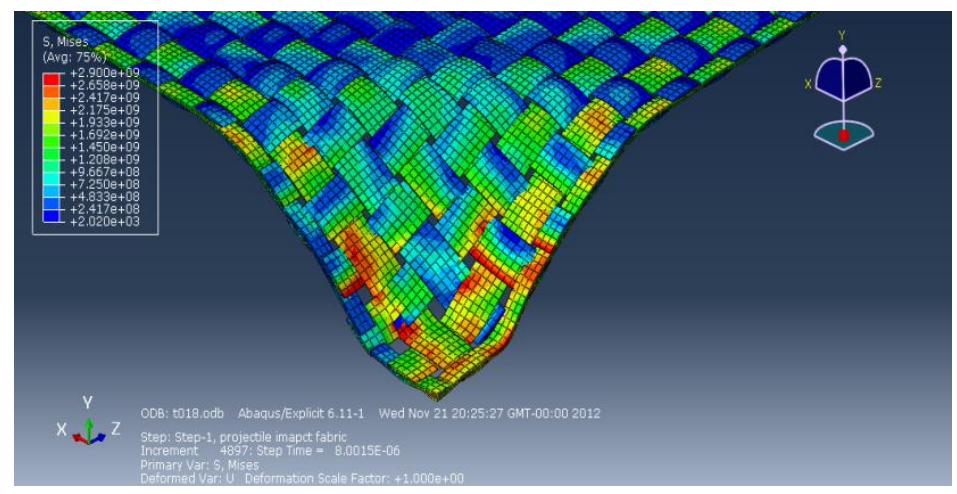


(b) $8 \mu \mathrm{s}$

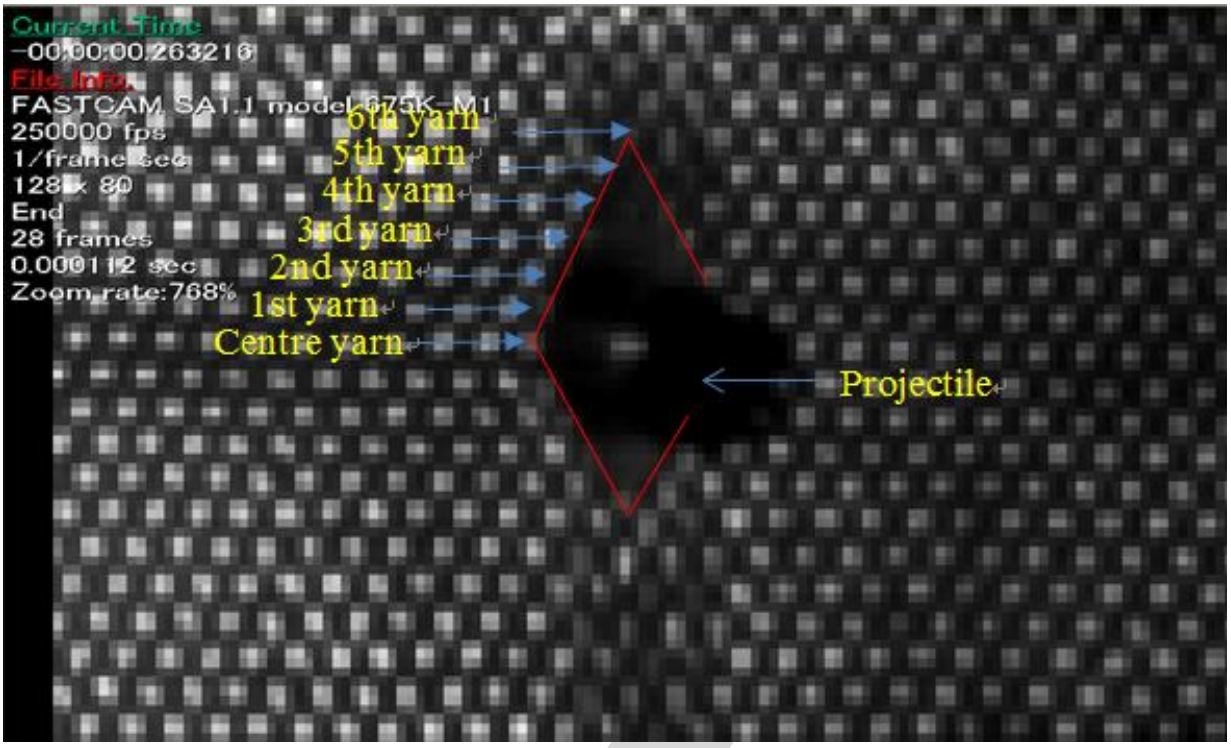

(a') $8 \mu \mathrm{s}$

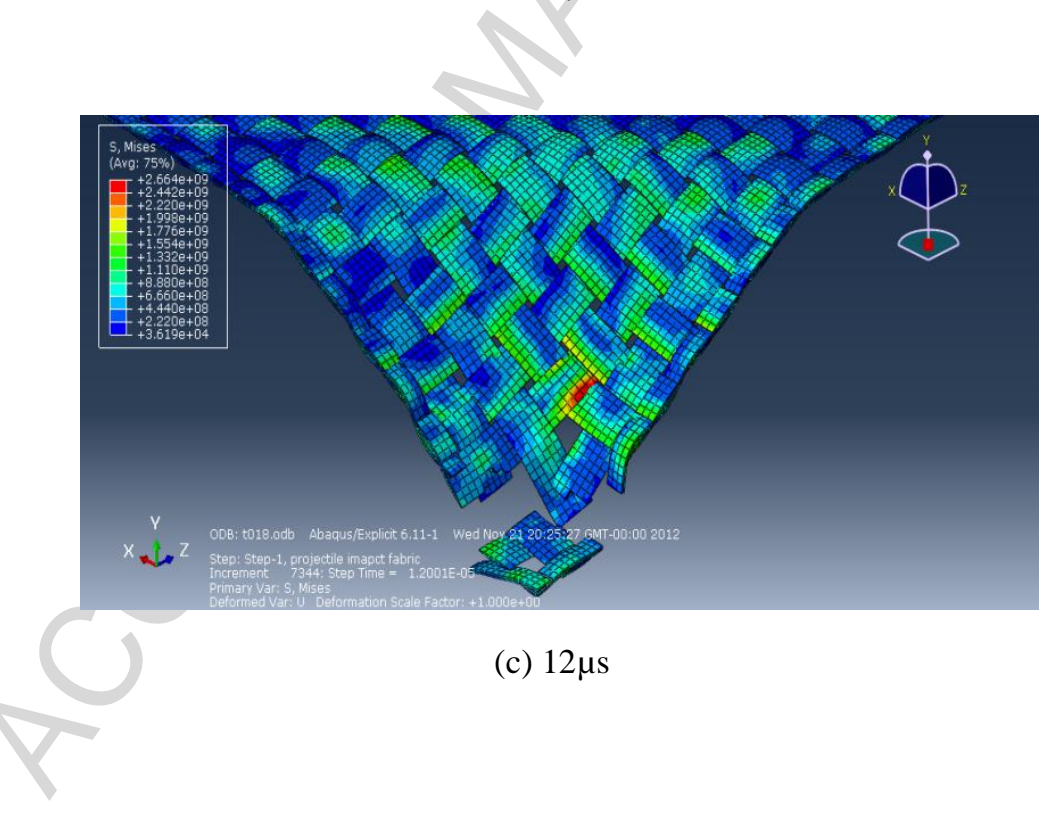




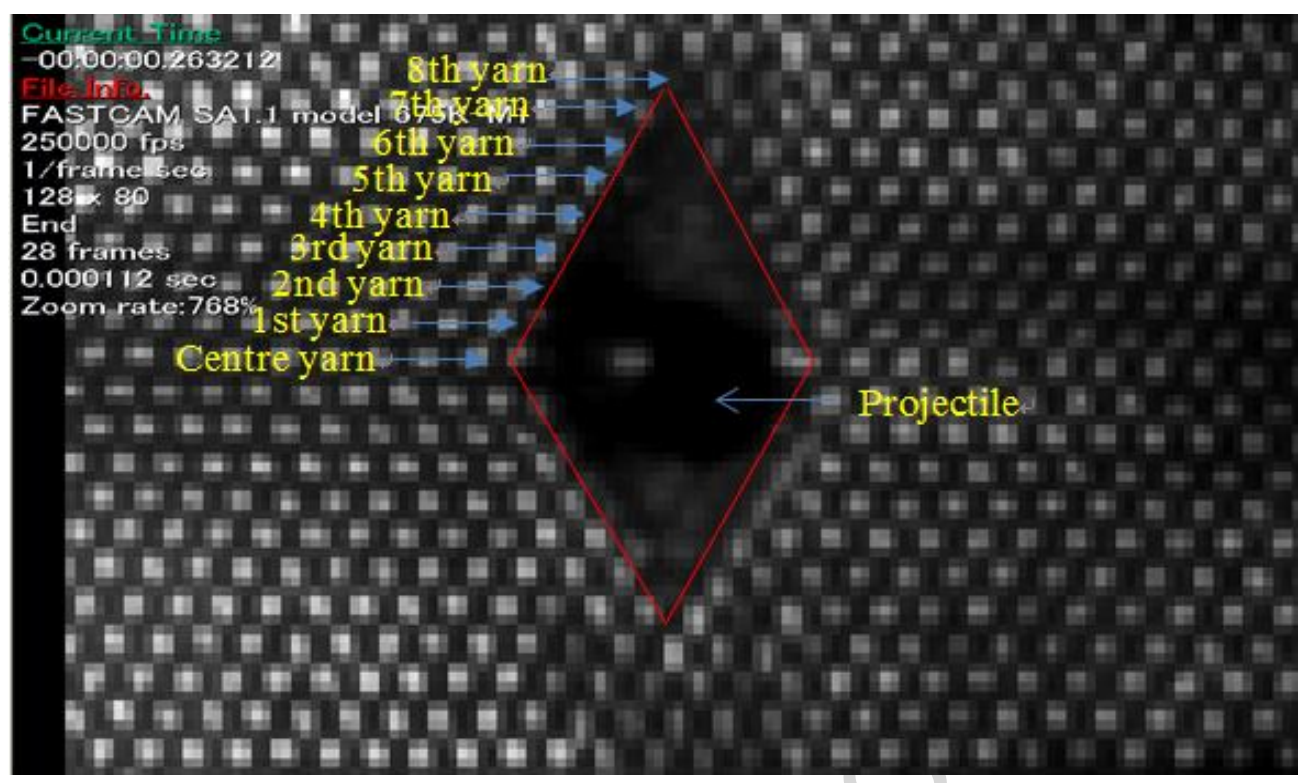

(c') $12 \mu \mathrm{s}$

Figure 8 Comparison of the transverse wave propagation between the $\mathrm{FE}(\mathrm{a}),(\mathrm{b}),(\mathrm{c})$ and the recorded photographs from high speed camera $\left(a^{\prime}\right)\left(b^{\prime}\right)\left(c^{\prime}\right)$.

\section{Results}

The effects of inter-yarn friction are investigated under two Young's moduli, one being 72 $\mathrm{GPa}$ and the other being $112 \mathrm{GPa}$. The $72 \mathrm{GPa}$ is set according to the Young's modulus of Twaron $^{\circledR}$ yarns $^{[5]}$. The $112 \mathrm{GPa}$ is set according to the Young's modulus of Dyneema ${ }^{\circledR}$ yarns $^{[24-26]}$. The other material properties like fracture strain and yield stress, yarn density、 fineness and Poisson's ratio of the two moduli are kept same to Twaron ${ }^{\circledR}$ yarns. These two cases are named as Twaron $^{\circledR}$ fabric model (TM) and Dyneema ${ }^{\circledR}$ fabric model (DM), respectively. A pair of coefficients of friction including the coefficient of static friction (CSF) and the coefficient of kinetic friction $(\mathrm{CKF})$ are set to indicate the variations of inter-yarn friction in the fabric. The CSF varies from 0 to 1 and CKF from 0.05 to 0.95 with 0.1 intervals. The impact velocity of the projectile in the FE simulation is set as $475 \mathrm{~m} / \mathrm{s}$ since it is an averaged impact velocity obtained in the ballistic experiments. The energy absorption computed in the following analyses is based on the entire fabric although the model in FE simulation is a quarter based. 


\subsection{Responses of primary yarns}

\subsubsection{Stress distribution on primary yarns}

The primary yarns are yarns directly contacting with the projectile. The positions of the selected representative primary yarns (warp yarn 2 and weft yarn 2) are shown in Figure 11. The tensile and shear stress distributions on the marked primary yarns under ballistic impacts are examined for both TM and DM.

\subsubsection{Tensile stress}

Tensile stress is a stress component along the axis of yarns. Generally, the distribution of the stress is non-uniform, where the stress near the impact centres is higher. It is hoped to be uniformly distributed into a larger area and propagate fast away from the impact point before the fabric failure. Figure 9 and 10 plot the tensile stress distributions on the selected two primary yarns in the cases of TM and DM, respectively. The horizontal axis is the distance from the impact centre. The time interval for each case is selected to be $3 \mu$ s. The end time points for TM and DM are selected as $6 \mu \mathrm{s}$ and $12 \mu \mathrm{s}$, after which the primary yarns begin to fail in each case.

Under the same material model, the tensile stress propagates at the same speed under different frictional levels. However, the inter-yarn friction affects the distribution of tensile stress on the primary yarns. It is noticeable that, near the impact centre, the tensile stress in the case of higher frictional level is higher than that of the lower frictional levels. Conversely, the tensile stress at the stress wave front away from the impact centre in the case of lower friction is higher than that of higher inter-yarn friction. This type of stress distribution indicates that the tensile stress concentrates more on the impact centre at higher levels of inter-yarn friction. Specially, focusing on the area with the radius of 3-5 $\mathrm{mm}$ from the impact centre where the yarn breakages take place for the used projectile, the tensile stress taken by the primary yarns at higher levels of inter-yarn friction is always 
higher than that at lower ones. Due to the limitation of the space, the tensile stress distributions on other primary yarns are not presented here but the distribution trend was found similar to these in the representative yarns. The reason for the higher tensile stress in models with higher friction is that with the increase of inter-yarn friction, the yarn movements are more likely to be hindered at the interlacing points, and less tensile stress can pass over the crossovers and transmit to wider area. The high tensile stress near the impact centre is harmful because it will lead to the premature tensile failure of the fabric. For this reason, the primary yarns would fail a little earlier when the inter-yarn friction is higher.

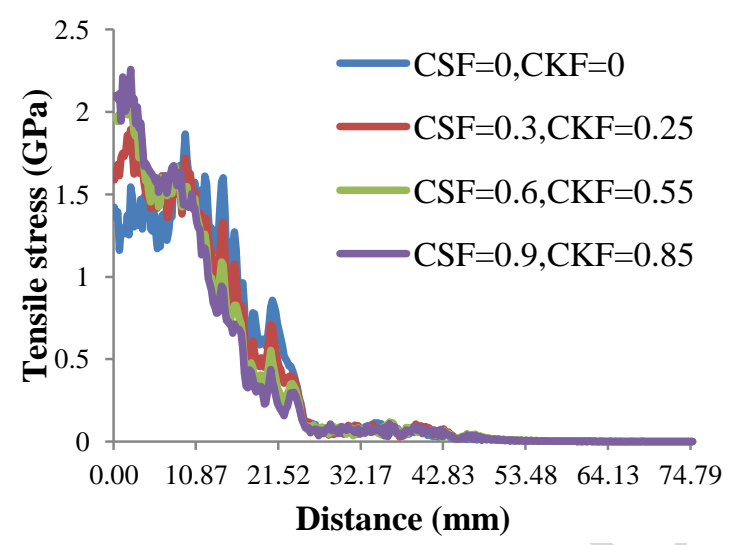

(a) warp yarn 2 at $3 \mu \mathrm{s}$

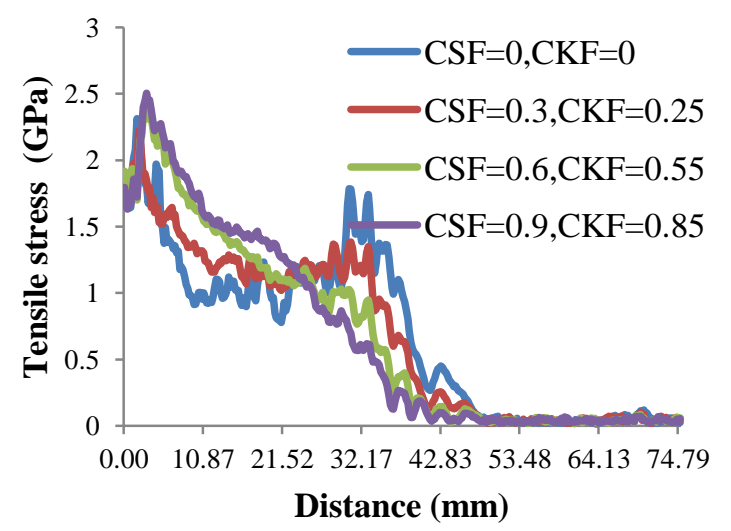

(b) warp yarn 2 at $6 \mu \mathrm{s}$

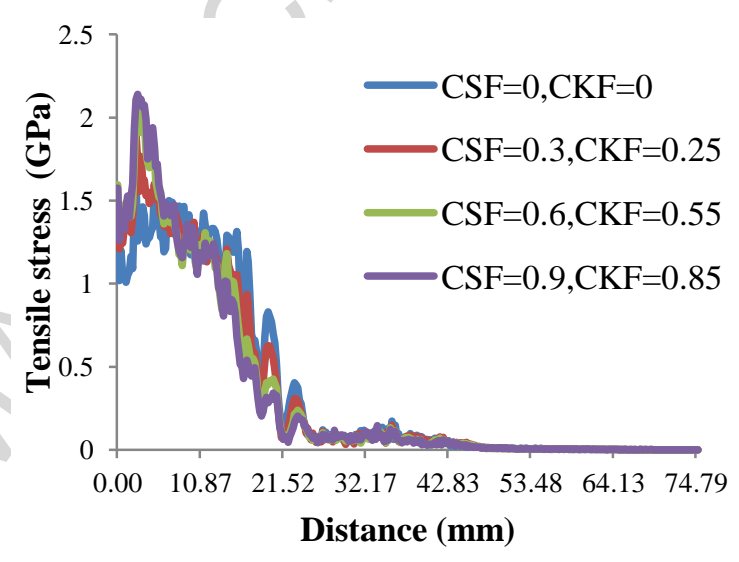

(a') weft yarn 2 at $3 \mu \mathrm{s}$

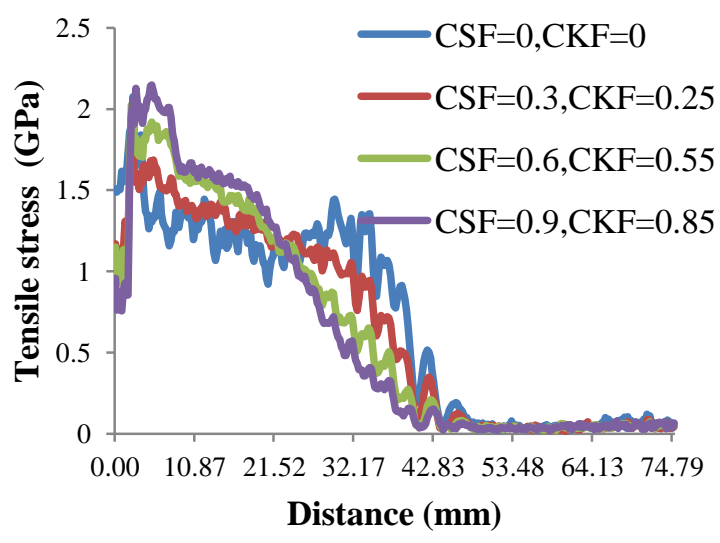

(b') weft yarn 2 at $6 \mu \mathrm{s}$

Figure 9 The distribution of tensile stress on the primary yarns in TM 72 GPa case 


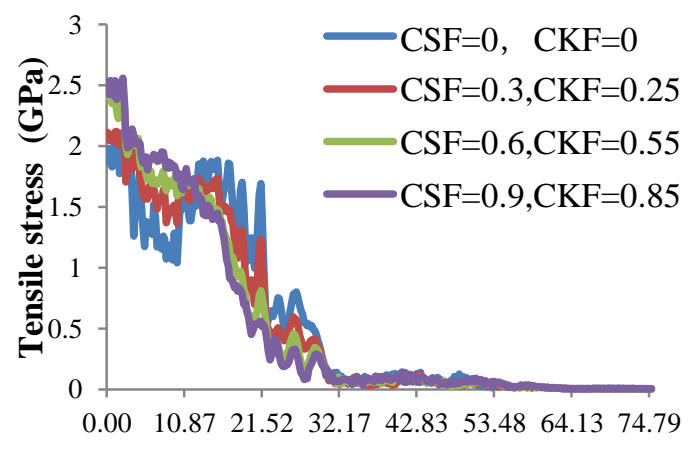

Distance (mm)

(a) warp yarn 2 at $3 \mu \mathrm{s}$

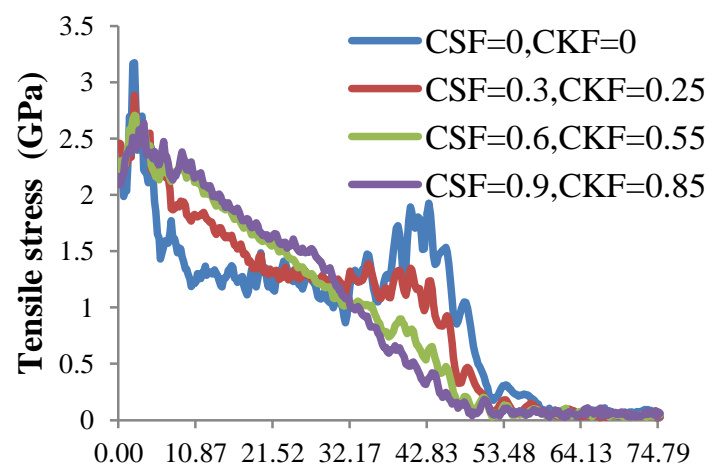

Distance (mm)

(b) warp yarn 2 at $6 \mu \mathrm{s}$

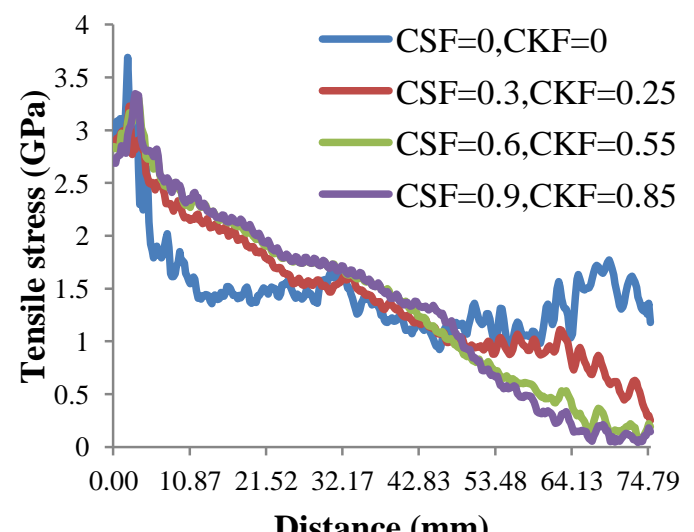

Distance (mm)

(C) warp yarn 2 at $9 \mu \mathrm{s}$

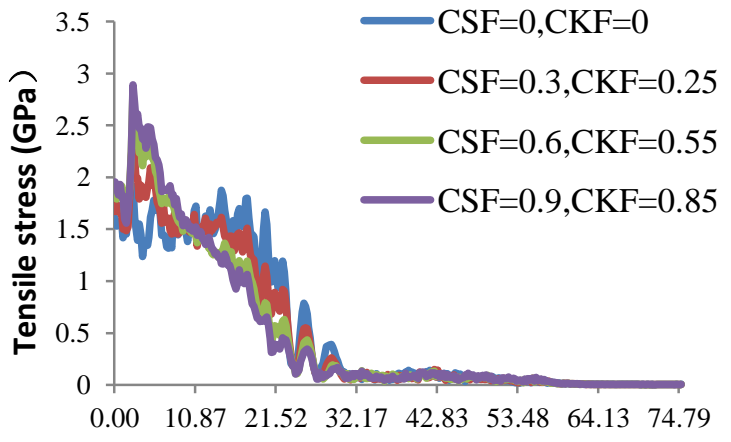

Distance (mm)

(a') weft yarn 2 at $3 \mu \mathrm{s}$

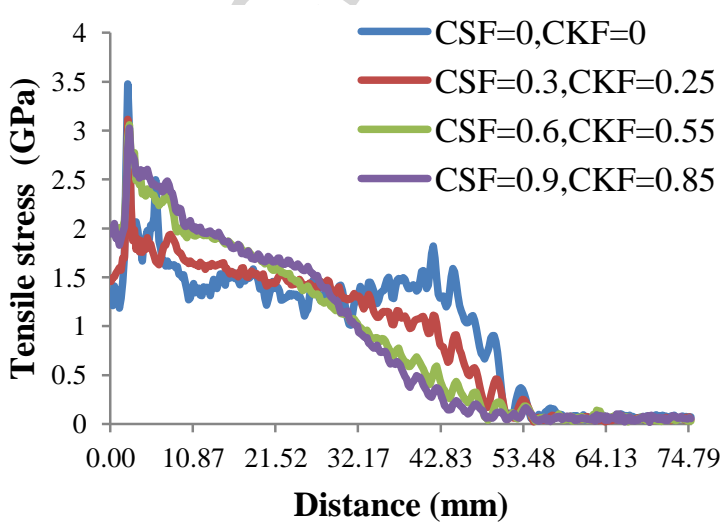

(b') weft yarn 2 at $6 \mu \mathrm{s}$

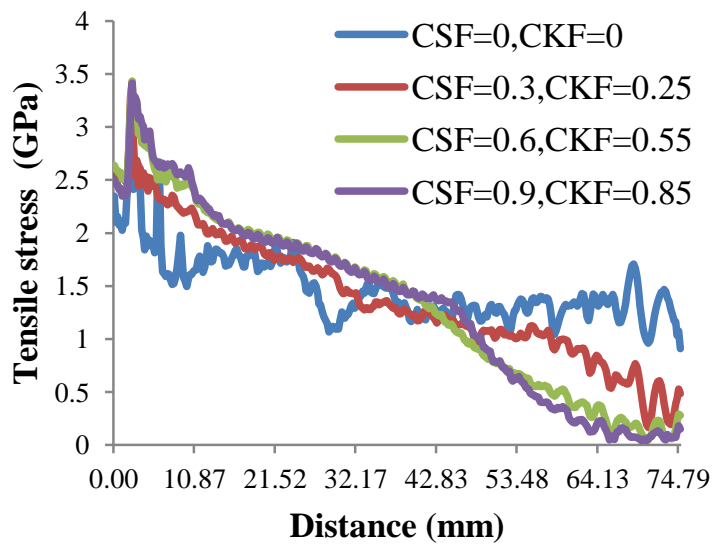

(C') weft yarn 2 at $9 \mu \mathrm{s}$ 


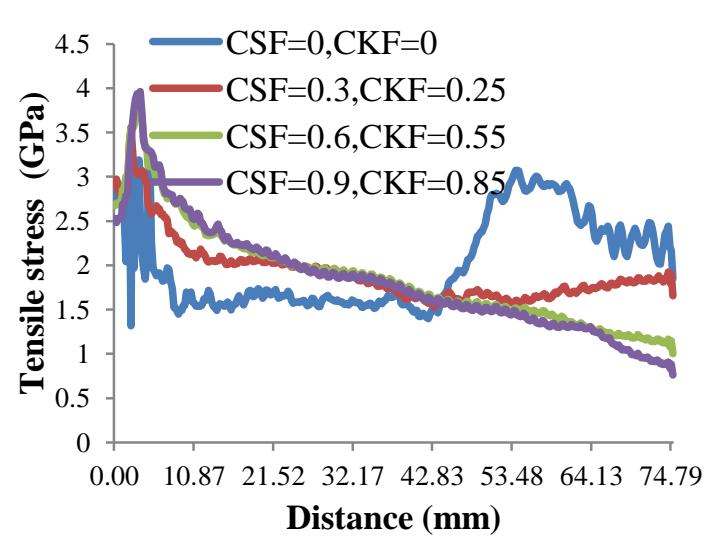

(d) warp yarn 2 at $12 \mu \mathrm{s}$

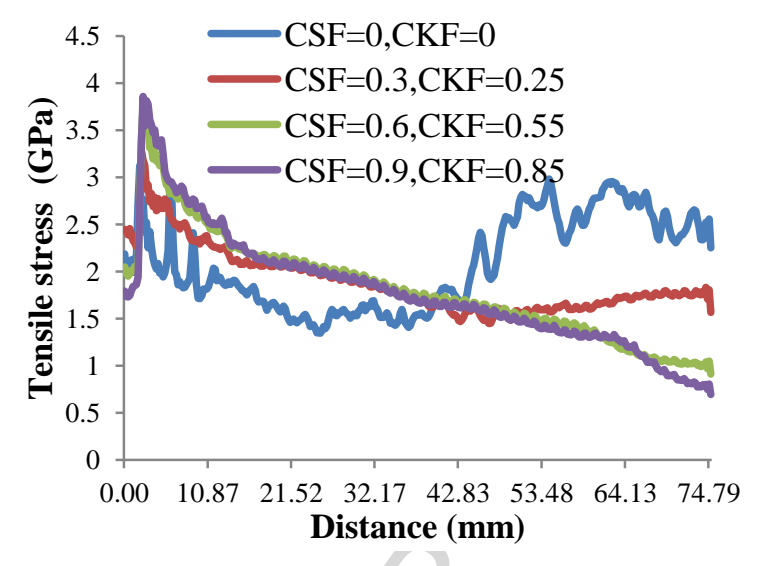

(d') weft yarn 2 at $12 \mu \mathrm{s}$

Figure 10 The distribution of tensile stress on the primary yarns in DM 112 GPa case

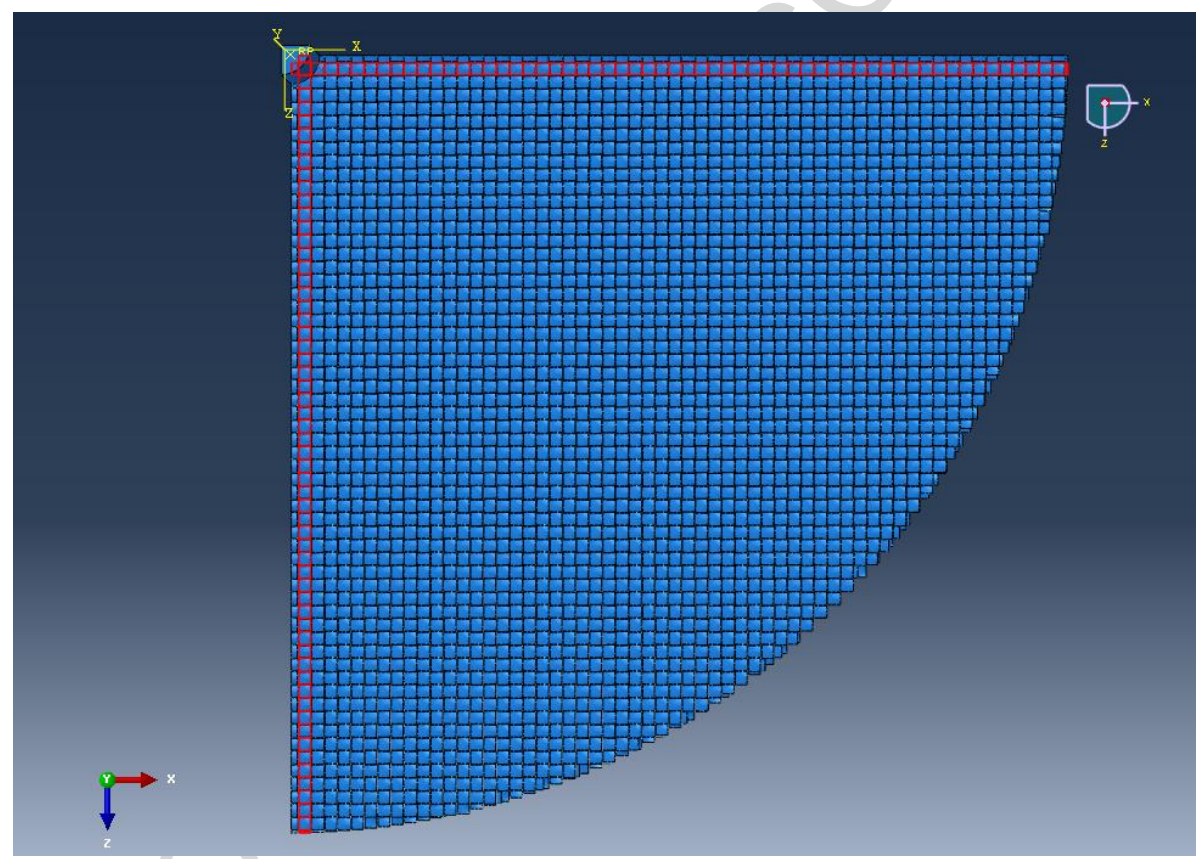

Figure 11 The position of the selected primary yarns in red colour: warp yarn 2 along the $x$ axis and weft yarn 2 along the $z$ axis

\subsubsection{Shear stress}

Apart from the tensile stress acted on the primary yarns during ballistic impact, the yarns are subjected to the shear action as well ${ }^{[27]}$. The shear stress mainly refers to the stress acting on the cross-section of a yarn. To clarify the effects of inter-yarn friction on the shear action, the distribution of shear stress on the primary yarns is also investigated. Warp yarn 2 and weft yarn 2 in Figure 11 are still selected as the representatives of the primary 
yarns. The distributions of the shear stress on these two yarns under the material models of TM $72 \mathrm{GPa}$ and DM $112 \mathrm{GPa}$ during the impact event at different frictional levels are presented in Figure 12 and Figure 13 below, respectively. The time points selected are similar to those in Figure 9 and 10.

At $3 \mu \mathrm{s}$, the shear stress on the primary yarns located in the narrow region 3-4 mm away from the impact centre is found larger at the higher frictional levels. This region is right around the edge area of the cylindrical projectile. In other parts of the primary yarns, the shear stress fluctuates on a small scale, and the inter-yarn friction has no effects. As the time advances, the peak shear stress is increased but the wide of the region is not significantly changed. The shear stress keeps higher value at higher level of the inter-yarn friction until $6 \mu \mathrm{s}$ for TM and $12 \mu \mathrm{s}$ for DM near the edge of the projectile. It should be mentioned here that the shear stress distribution on the other primary yarns also shows such trends although they are not presented here because of limitation of space. All in all, during the whole process, the regions in the primary yarns near the projectile edge at higher levels of inter-yarn friction are constantly loaded the higher shear stress. The reason may be that the higher inter-yarn friction can increase the transverse modulus of the fabric, which has been analysed by Briscoe $\mathrm{B}$ and Motamedi $\mathrm{F}^{[15]}$. The higher transverse modulus means the fabric become much stiffer. Generally, with the same impact force, a much stiffer plane matter would fail by more shear action compared with a softer one. Vice versa, the fabric's failure would be attributed to more shear action at higher levels of inter-yarn friction.
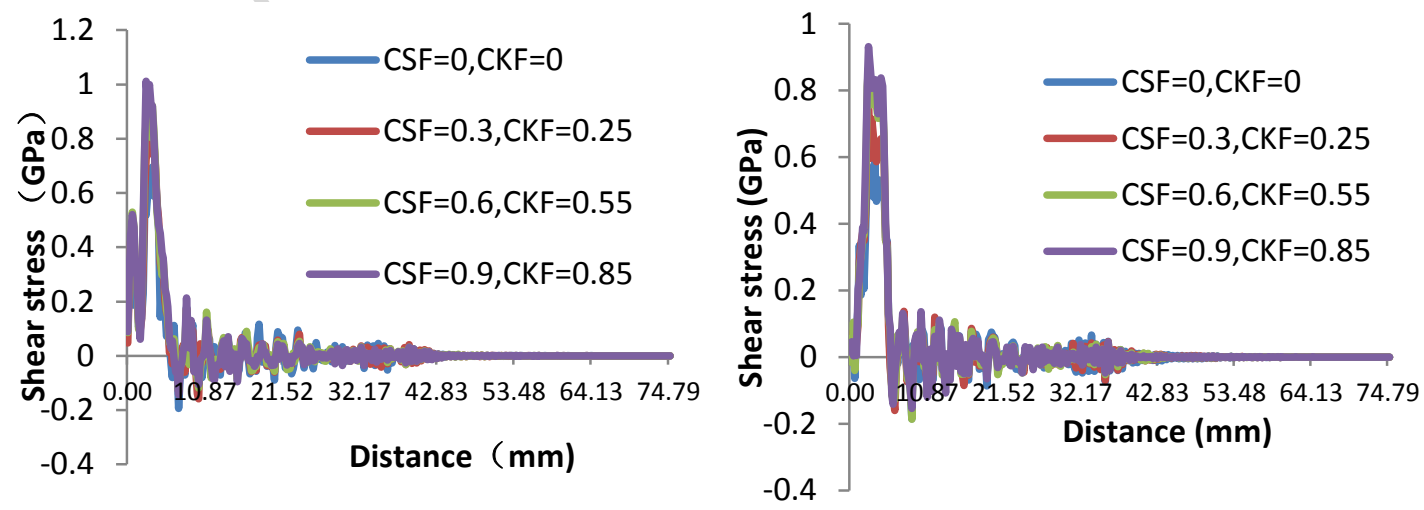
(a) warp yarn 2 at $3 \mu \mathrm{s}$

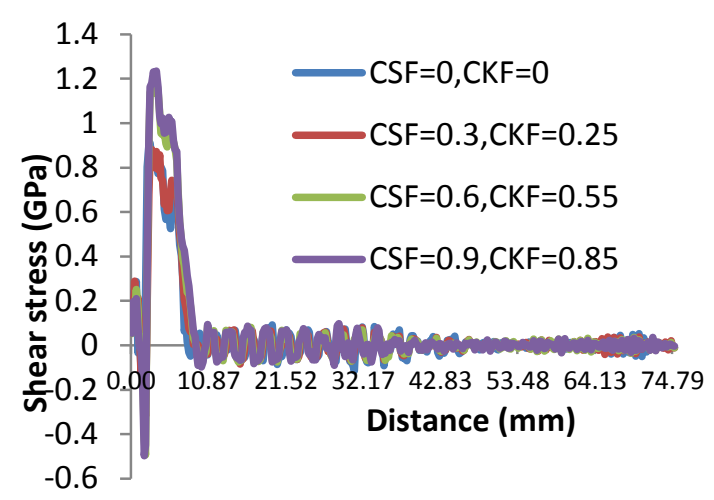

(b) warp yarn 2 at $6 \mu \mathrm{s}$ (a') weft yarn 2 at $3 \mu \mathrm{s}$

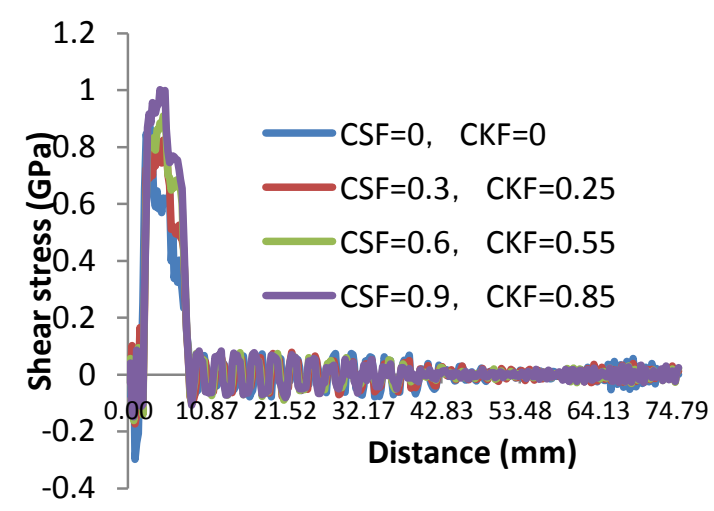

(b') weft yarn 2 at $6 \mu \mathrm{s}$

Figure 12 The distribution of shear stress on the primary yarns in TM 72 GPa case

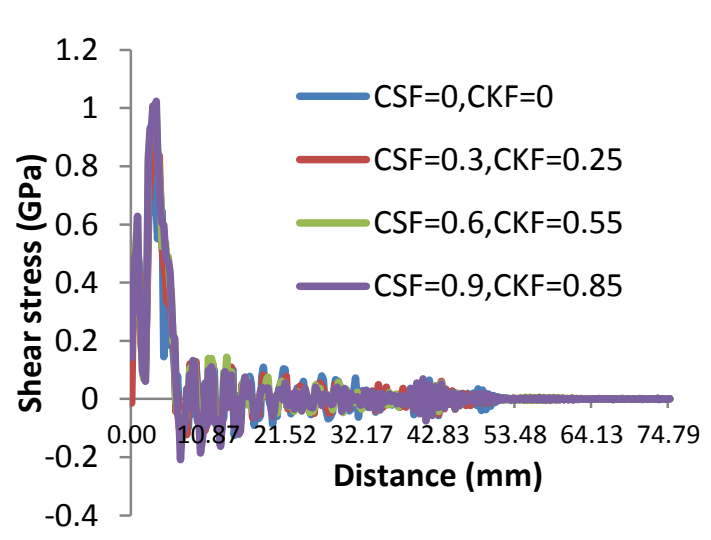

(a) warp yarn 2 at $3 \mu \mathrm{s}$

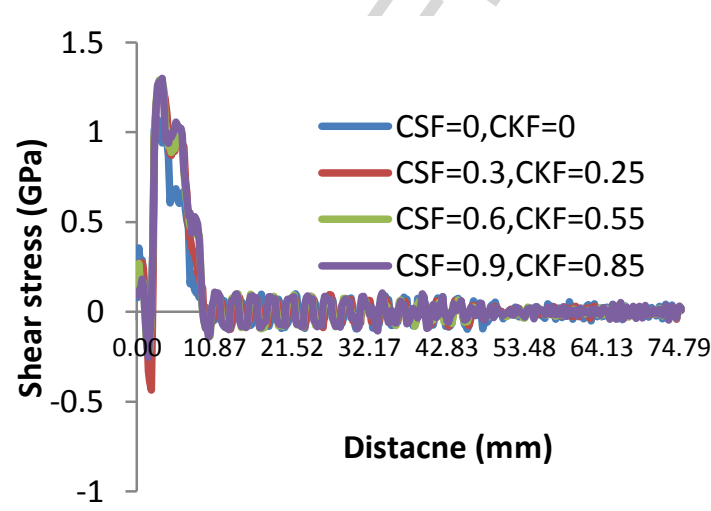

(b) warp yarn 2 at $6 \mu \mathrm{s}$

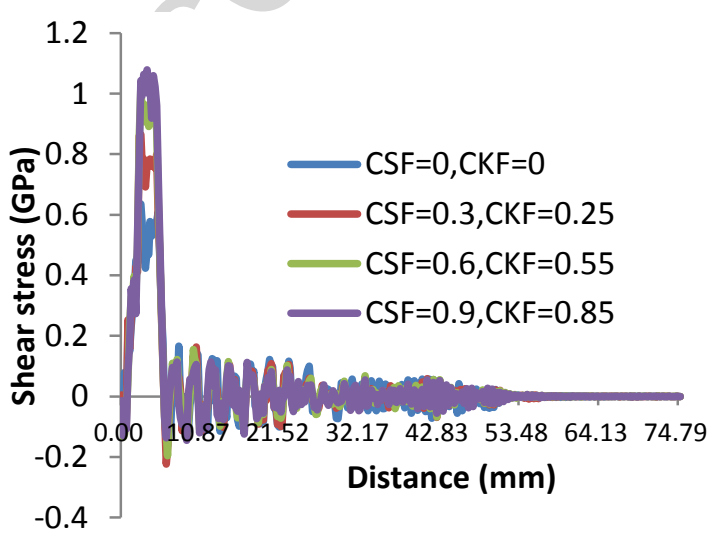

(a') weft yarn 2 at $3 \mu \mathrm{s}$

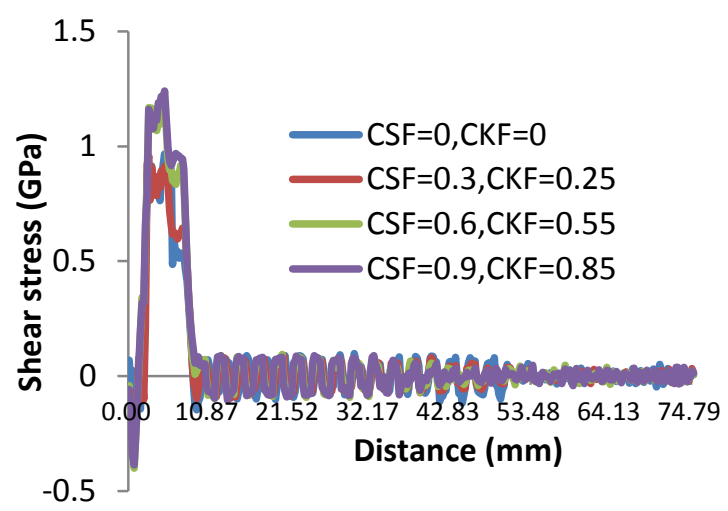

(b') weft yarn 2 at $6 \mu \mathrm{s}$ 


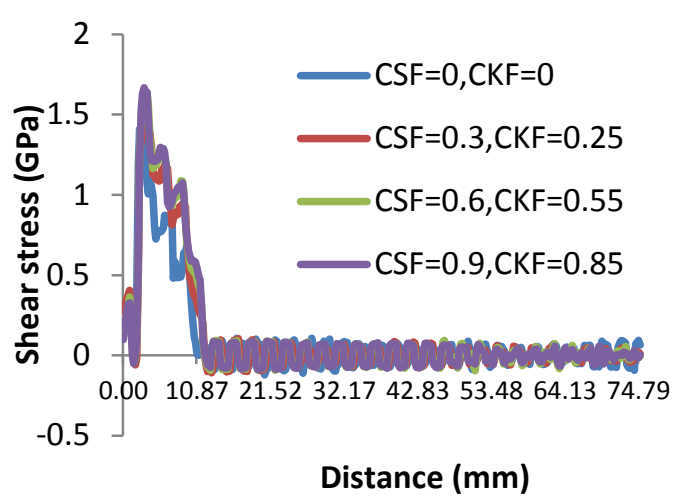

(c) warp yarn 2 at $9 \mu \mathrm{s}$

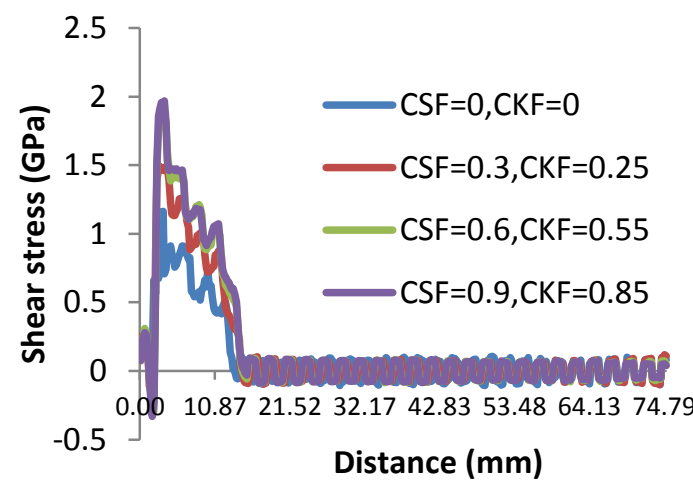

(d) warp yarn 2 at $12 \mu \mathrm{s}$

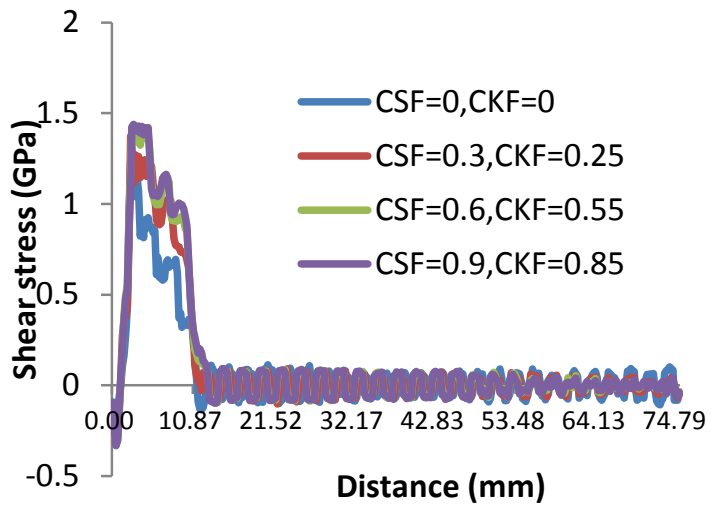

(c') weft yarn 2 at $9 \mu \mathrm{s}$

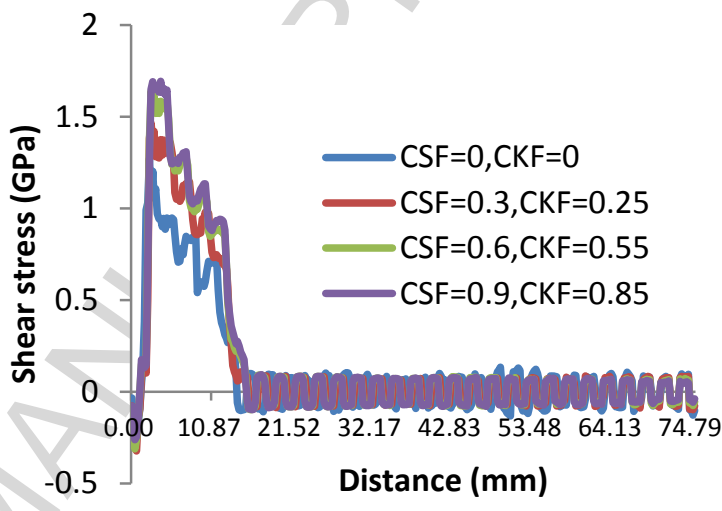

(d') weft yarn 2 at $12 \mu \mathrm{s}$

Figure 13 The distribution of shear stress on the primary yarns in DYM 112 GPa case

\subsubsection{Sliding of primary yarns}

The sliding of primary yarns is responsible for the structure stability in the impact centre, in other words, it decides whether the fabric will be destroyed by "wedge through" of the projectile or not. Figure 14 and 15 compare the sliding of primary yarns among selected three levels of inter-yarn friction in the impact area during the whole impact process for TM and DM, respectively. In the TM model, there are always two and half primary yarns contacting with the nose face of the projectile until $10 \mu \mathrm{s}$ in the two higher friction conditions in each direction. However, only one and half primary yarns are left contact in each direction in zero friction level from $5 \mu$ s onwards. In the DM model, at $3 \mu \mathrm{s}$, two and half primary yarns in each direction come into contact with the flat nose face of the projectile at each frictional condition. From $6 \mu$ s onwards, two of the primary yarns at the 
edge of the cylinder begin to slide away from the projectile face in the zero friction level and only one and half primary yarn are left until $9 \mu$ s. For the other two frictional conditions, two and half primary yarns in each direction are always kept contact with the face of projectile until $15 \mu \mathrm{s}$. The sliding of the primary yarns affected by inter-yarn friction can be illustrated by Figure 16. Less sliding of primary yarns away from the projectile at the impact centre means less "wedge through" ${ }^{[2]}$ and more resistance force to the projectile, which would prolong the time for full-penetration of the fabric. However, there is no difference at those much higher inter-yarn frictional levels, CSF of 0.70 and CKF of 0.65 , and CSF of 1.00 and CKF of 0.95 . The reason may be that the mobility of yarns at those levels of inter-yarn friction might be restricted to the same level.

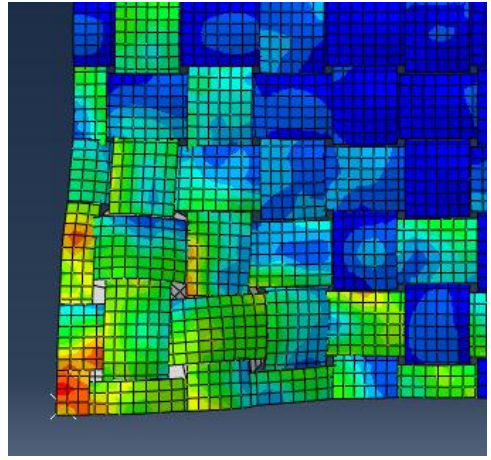

$2.5 \mu \mathrm{s}$

(a) $\mathrm{CSF}=0, \mathrm{CKF}=0$

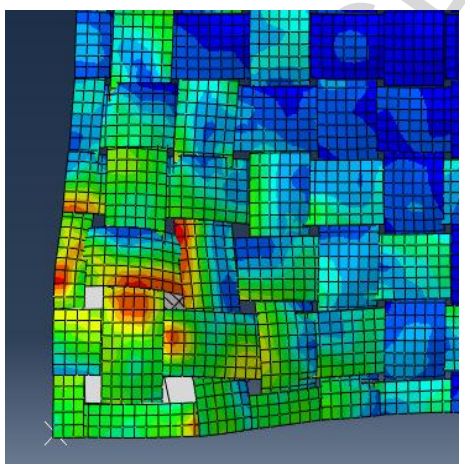

$5 \mu \mathrm{s}$

(a) $\mathrm{CSF}=0, \mathrm{CKF}=0$

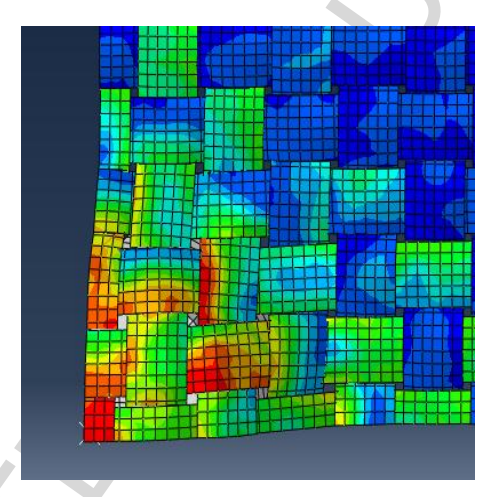

$2.5 \mu \mathrm{s}$

(b) $\mathrm{CSF}=0.7, \mathrm{CKF}=0.65$

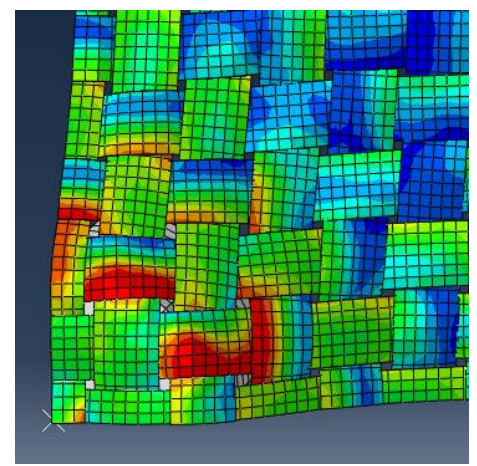

$5 \mu \mathrm{s}$

(b) $\mathrm{CSF}=0.7, \mathrm{CKF}=0.65$

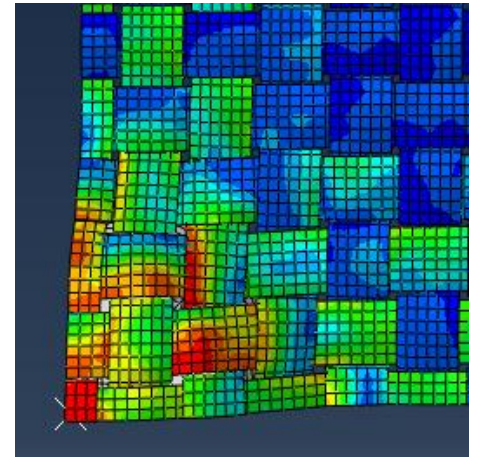

$2.5 \mu \mathrm{s}$

(c) $\mathrm{CSF}=1.0, \mathrm{CKF}=0.95$

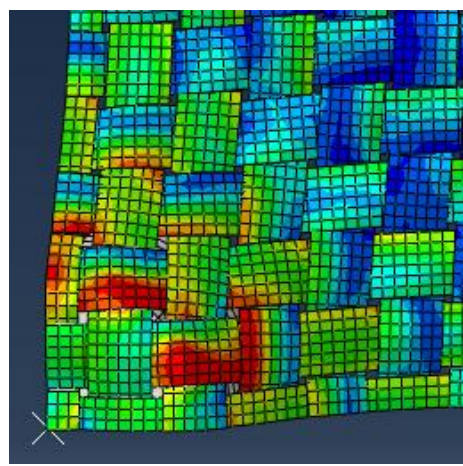

$5 \mu \mathrm{s}$

(c) $\mathrm{CSF}=1.0, \mathrm{CKF}=0.95$ 


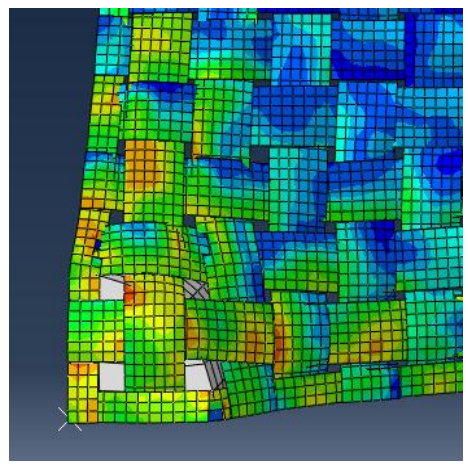

$7.5 \mu \mathrm{s}$

(a) $\mathrm{CSF}=0, \mathrm{CKF}=0$

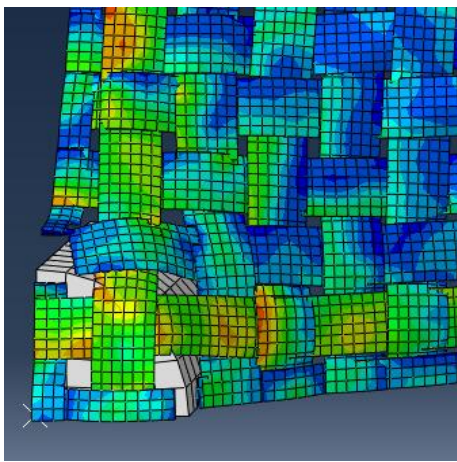

$10 \mu \mathrm{s}$

(a) $\mathrm{CSF}=0, \mathrm{CKF}=0$

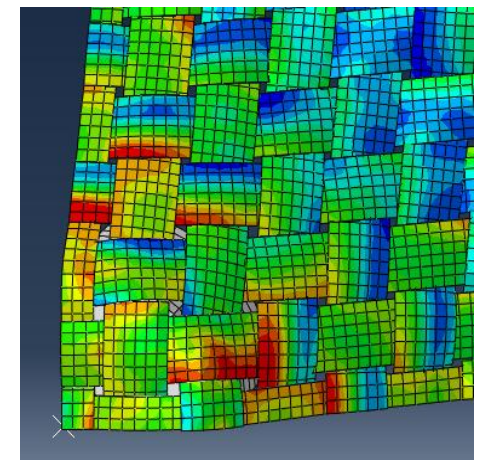

$7.5 \mu \mathrm{s}$

(b) $\mathrm{CSF}=0.7, \mathrm{CKF}=0.65$

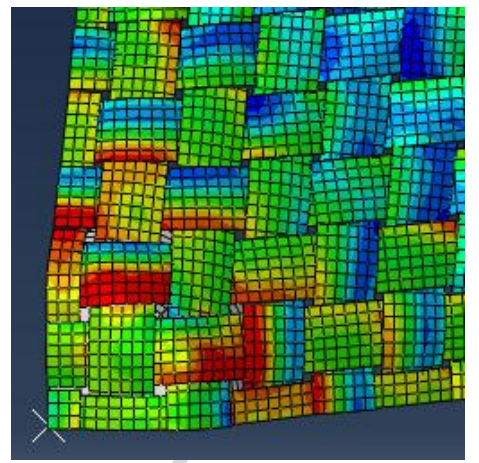

$7.5 \mu \mathrm{s}$

(c) $\mathrm{CSF}=1.0, \mathrm{CKF}=0.95$

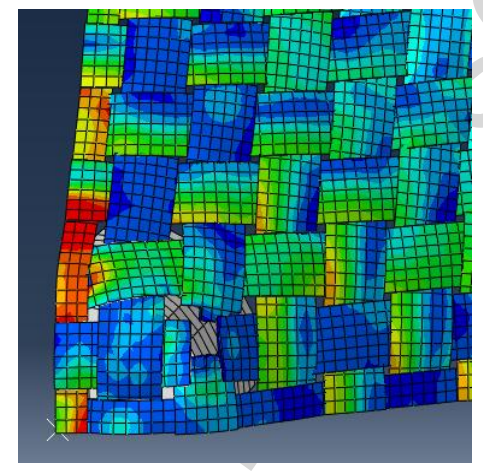

$10 \mu \mathrm{s}$

(b) $\mathrm{CSF}=0.7, \mathrm{CKF}=0.65$

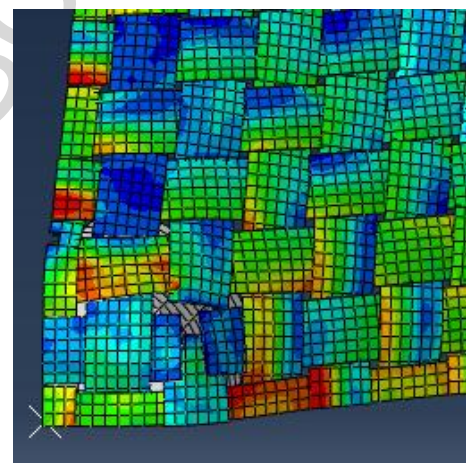

$10 \mu \mathrm{s}$

(c) $\mathrm{CSF}=1.0, \mathrm{CKF}=0.95$

Figure 14 The sliding of primary yarns at the impact area in TM 72 GPa case

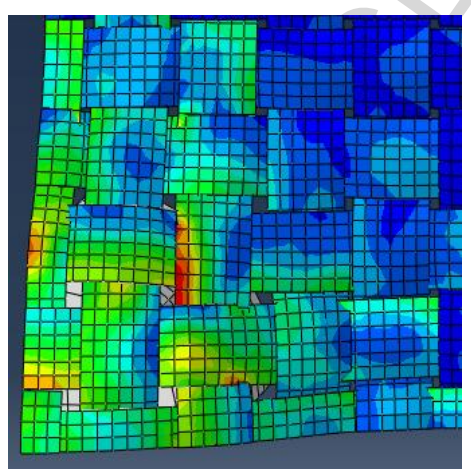

$3 \mu \mathrm{s}$

(a) $\mathrm{CSF}=0, \mathrm{CKF}=0$

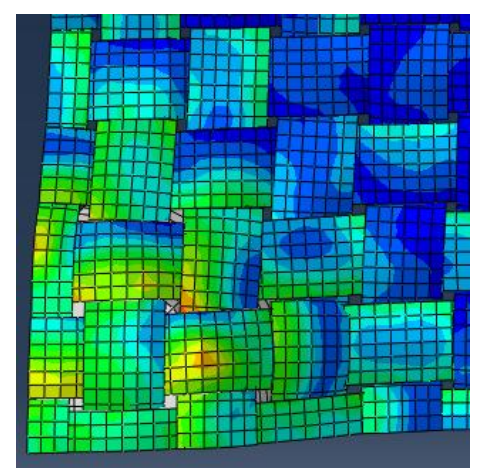

$3 \mu \mathrm{s}$

(b) $\mathrm{CSF}=0.7, \mathrm{CKF}=0.65$

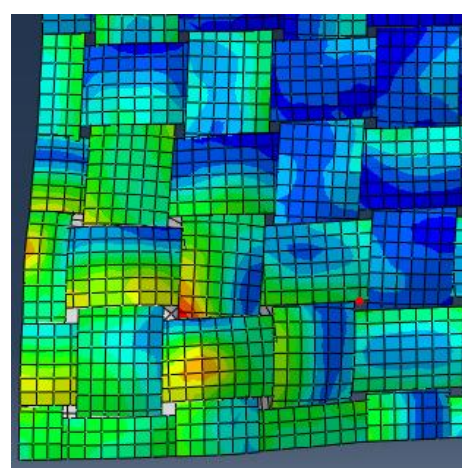

$3 \mu \mathrm{s}$

(c) $\mathrm{CSF}=1.0, \mathrm{CKF}=0.95$ 


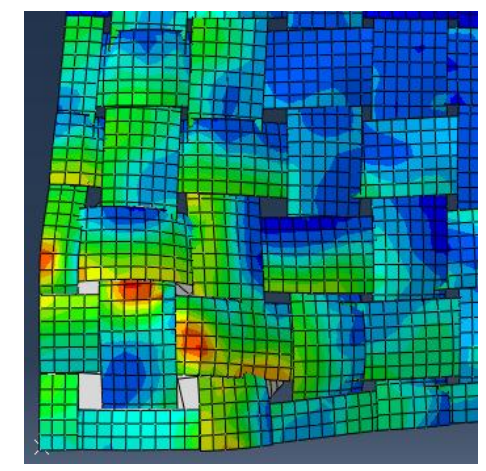

$6 \mu \mathrm{s}$

(a) $\mathrm{CSF}=0, \mathrm{CKF}=0$

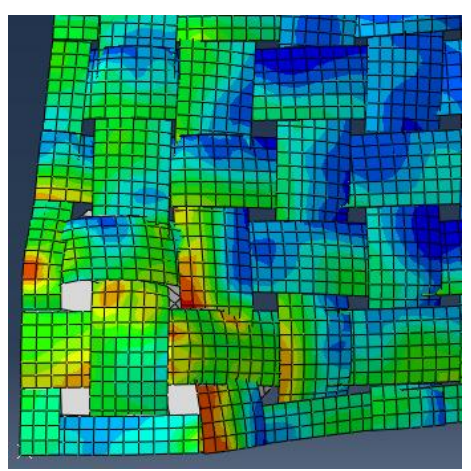

$9 \mu \mathrm{s}$

(a) $\mathrm{CSF}=0, \mathrm{CKF}=0$

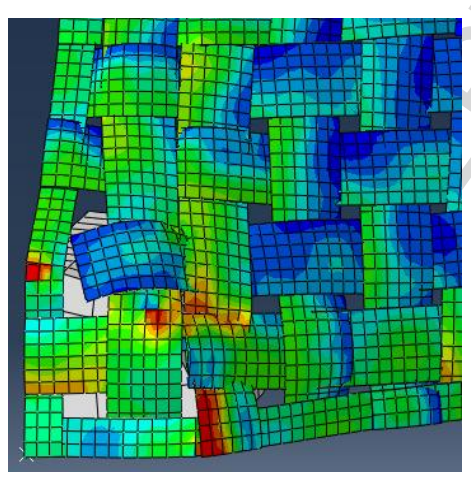

$12 \mu \mathrm{s}$

(a) $\mathrm{CSF}=0, \mathrm{CKF}=0$

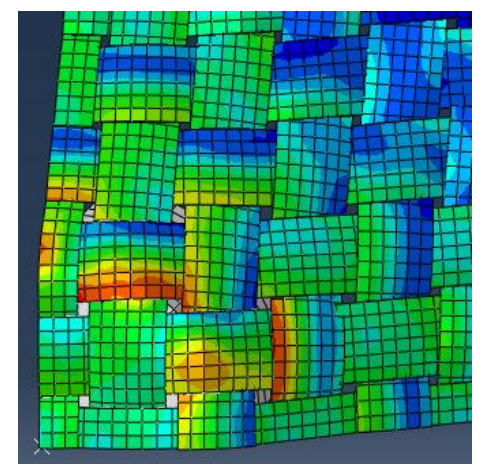

$6 \mu \mathrm{s}$

(b) $\mathrm{CSF}=0.7, \mathrm{CKF}=0.65$

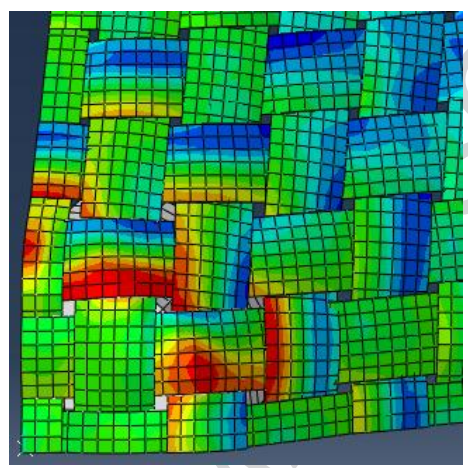

$9 \mu \mathrm{s}$

(b) $\mathrm{CSF}=0.7, \mathrm{CKF}=0.65$

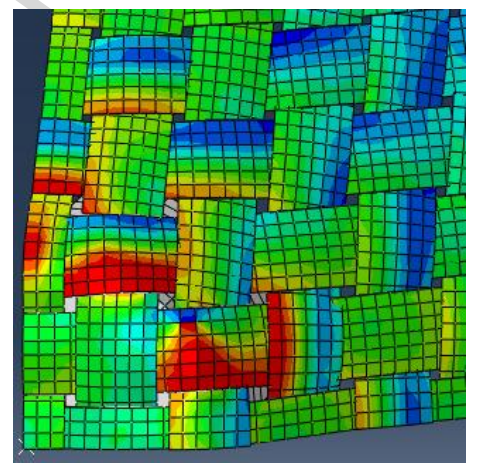

$12 \mu \mathrm{s}$

(b) $\mathrm{CSF}=0.7, \mathrm{CKF}=0.65$

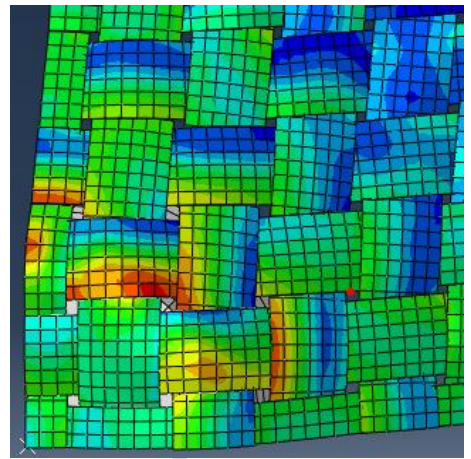

$6 \mu \mathrm{s}$

(c) $\mathrm{CSF}=1.0, \mathrm{CKF}=0.95$

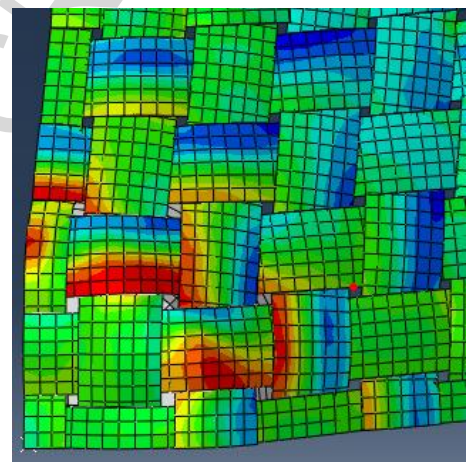

$9 \mu \mathrm{s}$

(c) $\mathrm{CSF}=1.0, \mathrm{CKF}=0.95$

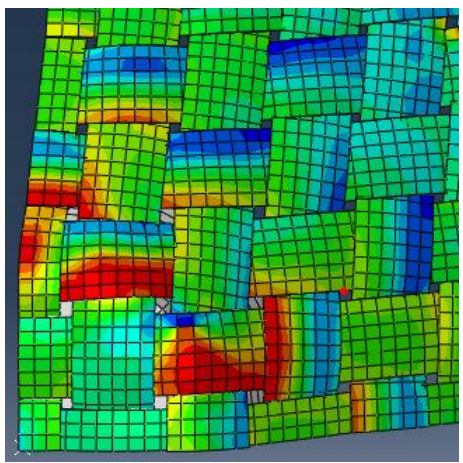

$12 \mu \mathrm{s}$

(c) $\mathrm{CSF}=1.0, \mathrm{CKF}=0.95$ 


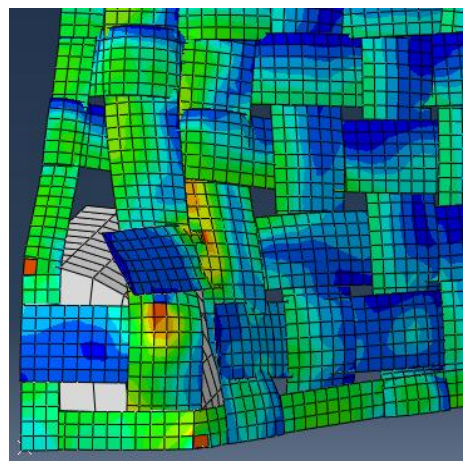

$15 \mu \mathrm{s}$

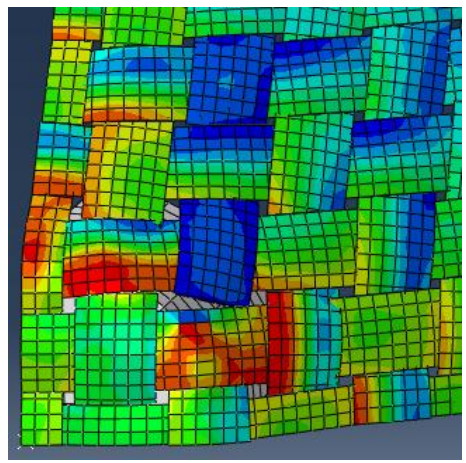

$15 \mu \mathrm{s}$

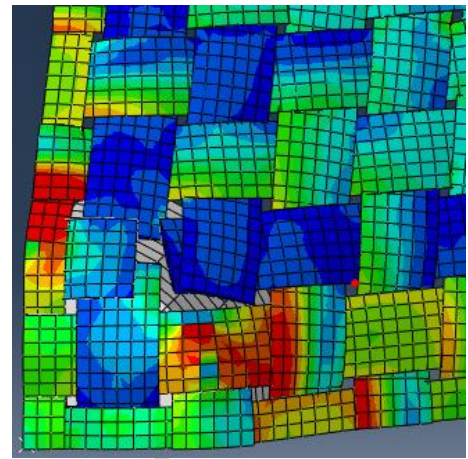

$15 \mu \mathrm{s}$

(a) $\mathrm{CSF}=0, \mathrm{CKF}=0$

(b) $\mathrm{CSF}=0.7, \mathrm{CKF}=0.65$

(c) $\mathrm{CSF}=1.0, \mathrm{CKF}=0.95$

Figure 15 The sliding of primary yarns at the impact area in DM 112 GPa case

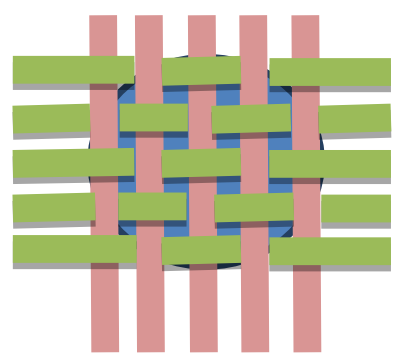

lower inter-yarn friction

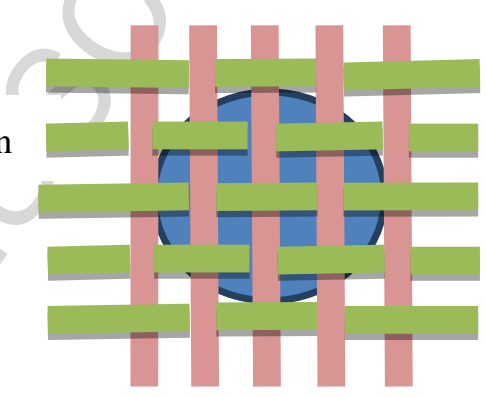

At the beginning of impact
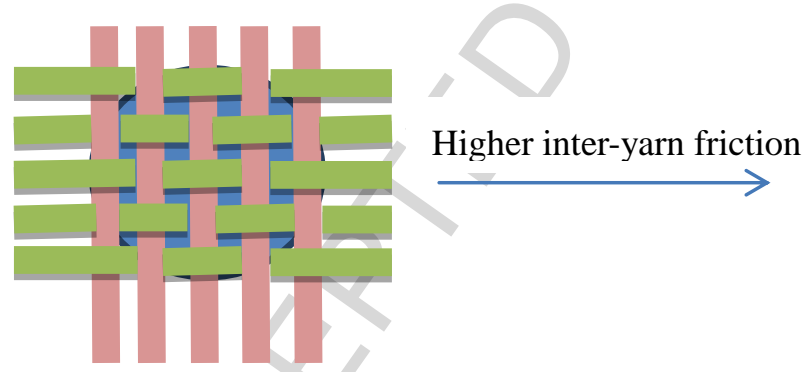

At the end of impact

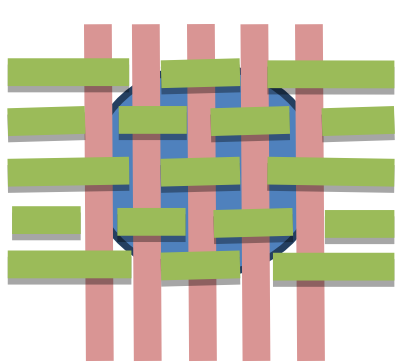

Figure 16 The sliding of primary yarns with impact proceeding

\subsection{Responses of secondary yarns}

\subsubsection{Stress distribution on secondary yarns}

The secondary yarns are yarns not directly in contact with the projectile. In other words, except primary yarns, all the other yarns in the fabric are secondary yarns. The impact stress is also taken by the secondary yarns. The stress mentioned here is the total stress including the tensile stress and shear stress. The total stress on them is analysed because the total stress represents the yarn's ability to share the impact energy, implying the 
amount of stress transferred away from the impact centre. To investigate the total stress shared by the secondary yarns, the von Mises stress $\sigma$ is used as the indicator. It is the combination of three primary stresses $\sigma_{\mathrm{x}}, \sigma_{\mathrm{y}}, \sigma_{\mathrm{z}}$ and three shear stresses $\tau_{\mathrm{xy}}, \tau_{\mathrm{yz}}, \tau_{\mathrm{xz}}$, as expressed in Equation 1. The von Mises stress at a material point equals to the total stress in the fibre approximately ${ }^{[6]}$. It is usually used to represent the total stress in the yarns in ABAQUS ${ }^{[27,28]}$. The yield stress is set as $2.9 \mathrm{GPa}$. Figure 17 and 18 shows the von Mises stress distribution on the selected secondary yarns in TM 72 GPa case and DM 112 GPa case individually. The positions of the selected two representative secondary yarns are described in Figure 19. The step time is set as $9 \mu$ s for TM 72 GPa case and $12 \mu$ s for DM $112 \mathrm{GPa}$ after which the fabric structures begins to be significantly damaged after the time points. It should be mentioned that the stress distributions on other secondary yarns near the impact centre follow the same rule. At a given time, the stress taken by the secondary yarns near the impact centre is always larger at higher levels of inter-yarn friction. In addition, the area where the secondary yarns take more stress at higher level of inter-yarn friction is enlarged with advance of time. There is a smaller area near the wave front where the secondary yarns take lower stress for larger inter-yarn friction. The stress distribution on the selected secondary yarns in DM is similar to that in TM. This type of stress distribution indicates that higher levels of inter-yarn friction results in the stress taken by the primary yarns more likely to disperse to the neighbouring secondary yarns. The possible reasons are that higher inter-yarn friction can increase the adhesive force between the two vertically intersecting yarns at the crossover, and make the yarns bow towards the impact centre more synchronously, and thus bring more the secondary yarns to share more stress.

$$
\sigma=\frac{1}{\sqrt{2}}\left[\left(\sigma_{x}-\sigma_{y}\right)^{2}+\left(\sigma_{y}-\sigma_{z}\right)^{2}+\left(\sigma_{z}-\sigma_{x}\right)^{2}+6\left(\tau_{x y}^{2}+\tau_{y z}^{2}+\tau_{z x}^{2}\right)\right]^{\frac{1}{2}}
$$




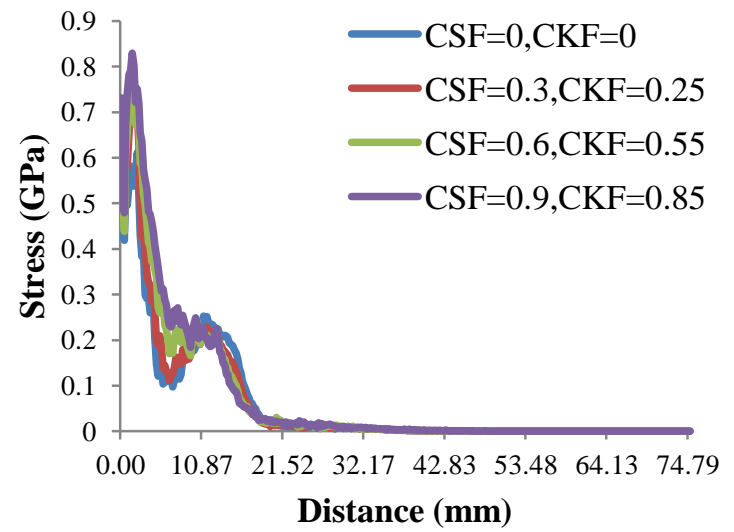

(a) warp yarn 5 at $3 \mu \mathrm{s}$

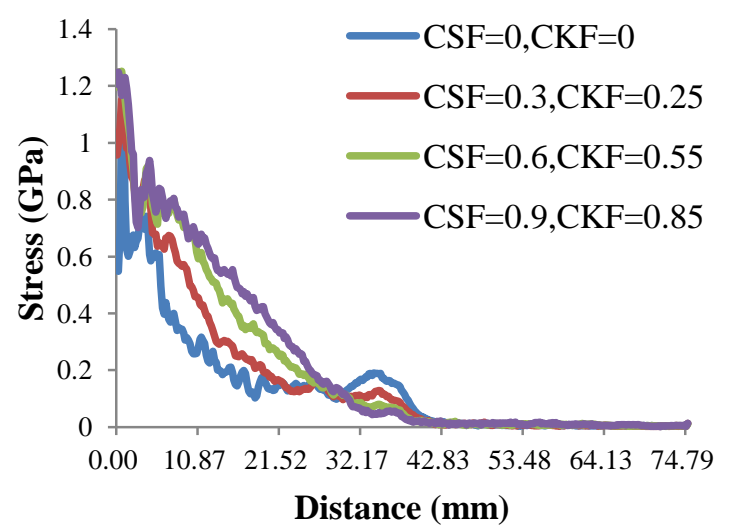

(b) warp yarn 5 at $6 \mu \mathrm{s}$

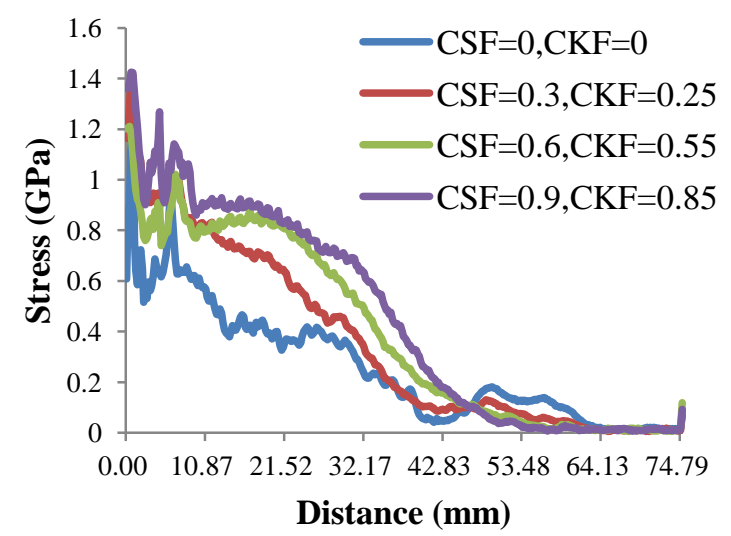

(c) warp yarn 5 at $9 \mu \mathrm{s}$

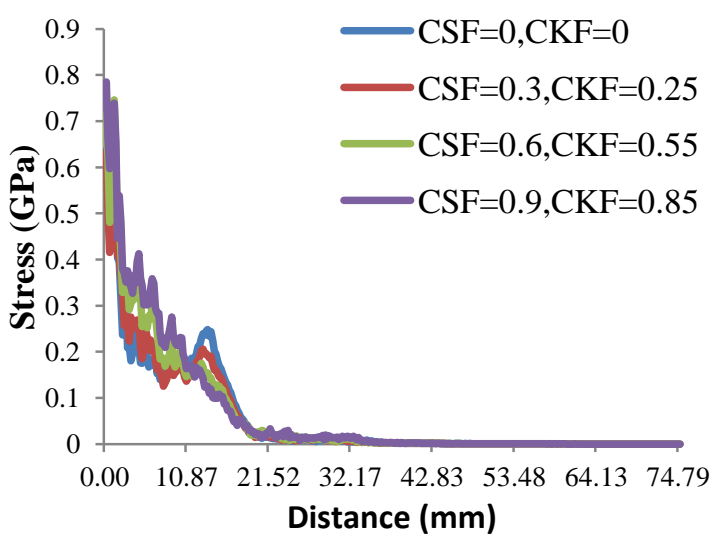

(a') weft yarn 5 at $3 \mu \mathrm{s}$

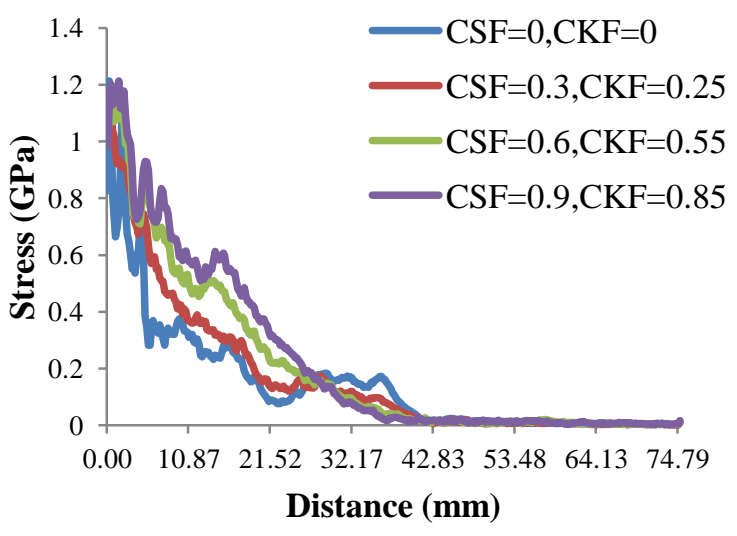

(b') weft yarn 5 at $6 \mu \mathrm{s}$

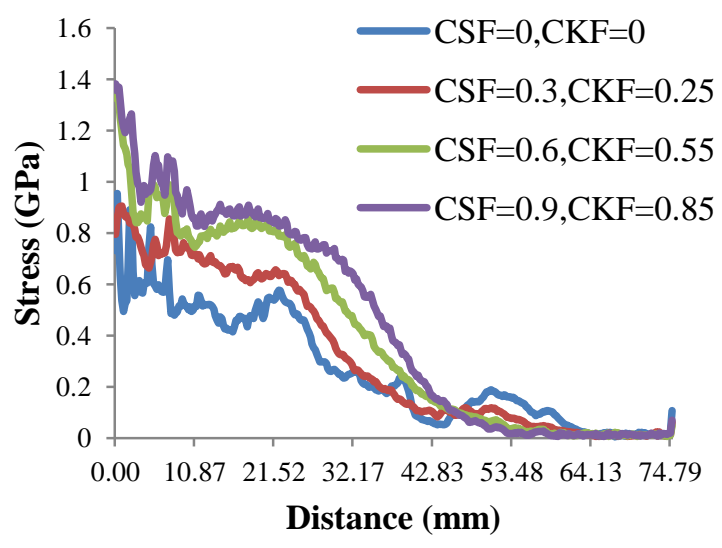

(c') weft yarn 5 at $9 \mu \mathrm{s}$

Figure 17 The von mises stress distribution on the secondary yarns in TM 72 Gpa 


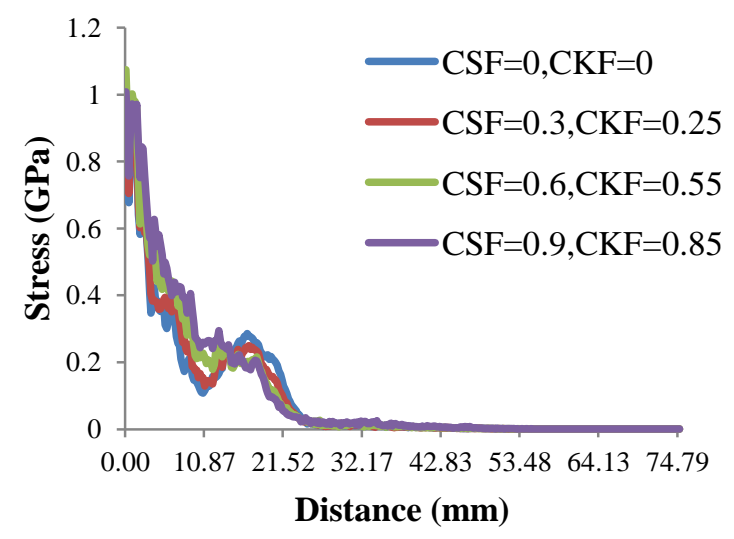

(a) warp yarn 5 at $3 \mu \mathrm{s}$

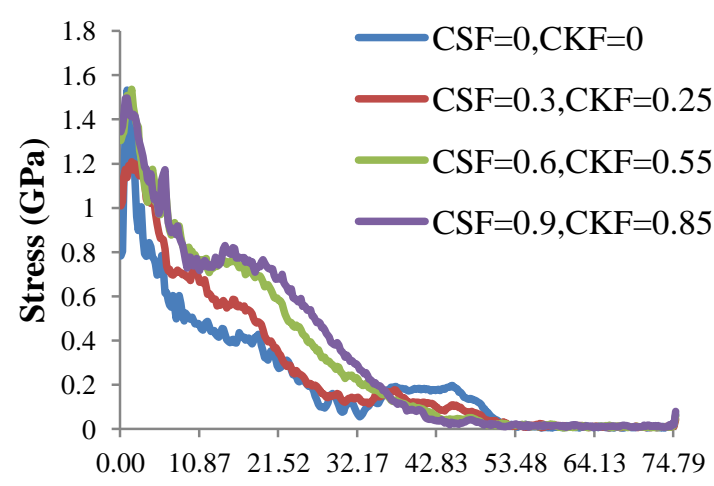

Distance (mm)

(b) warp yarn 5 at $6 \mu \mathrm{s}$

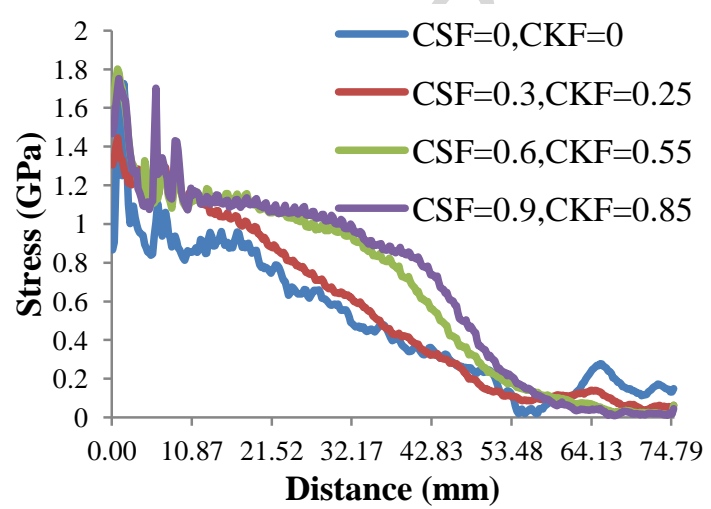

(c) warp yarn 5 at $9 \mu \mathrm{s}$

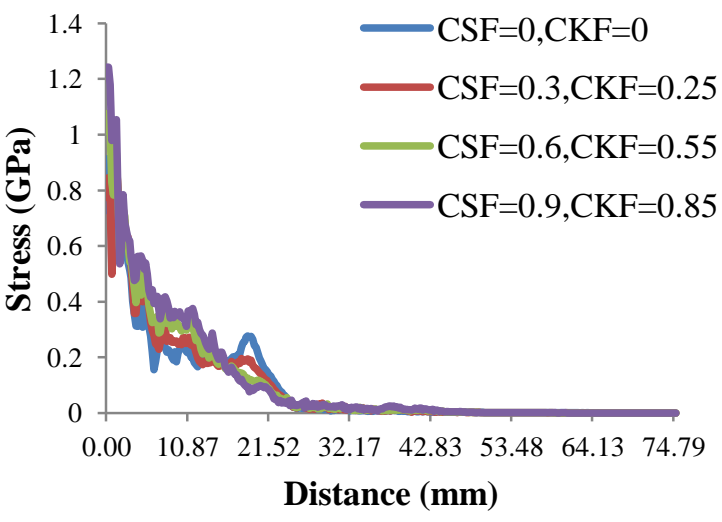

(a') weft yarn 5 at $3 \mu \mathrm{s}$

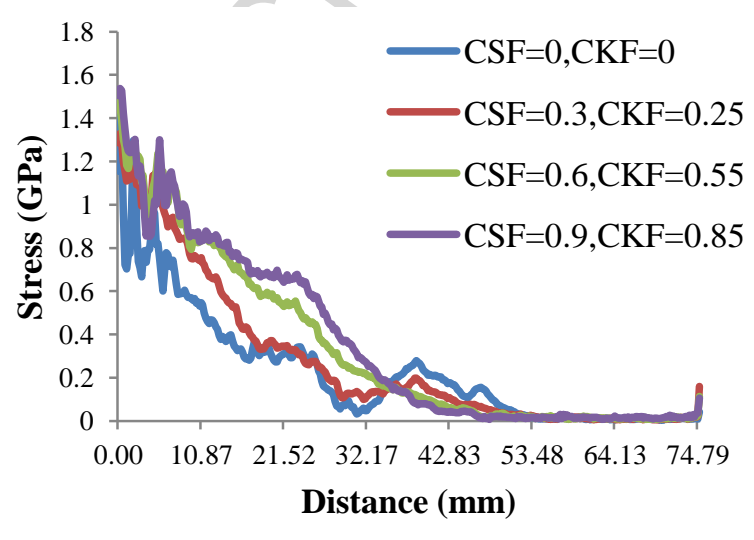

(b') weft yarn 5 at $6 \mu \mathrm{s}$

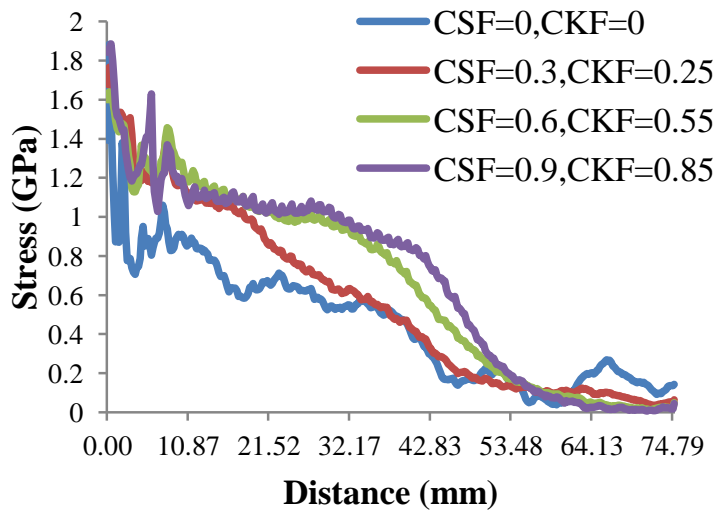

(c') weft yarn 5 at $9 \mu \mathrm{s}$ 


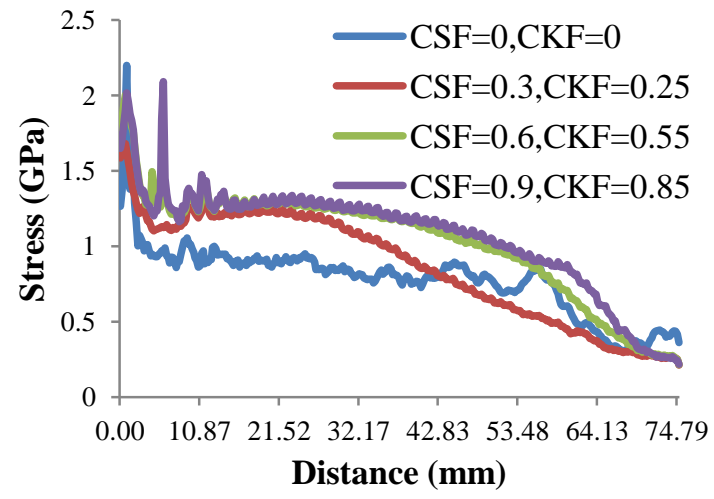

(d) warp yarn 5 at $12 \mu \mathrm{s}$

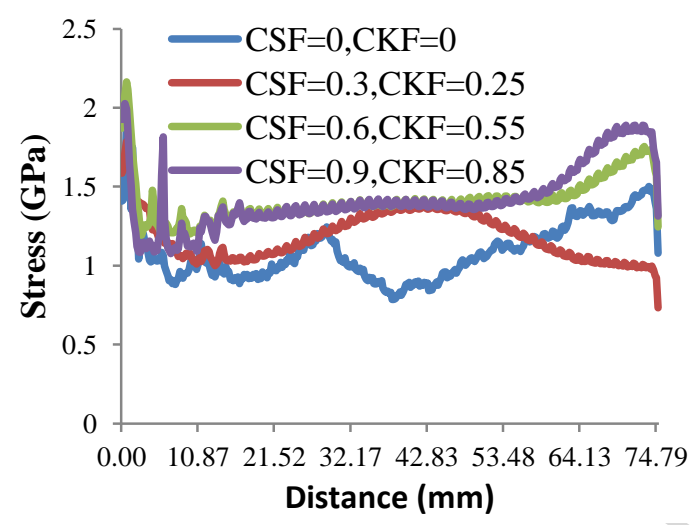

(e) warp yarn 5 at $15 \mu \mathrm{s}$

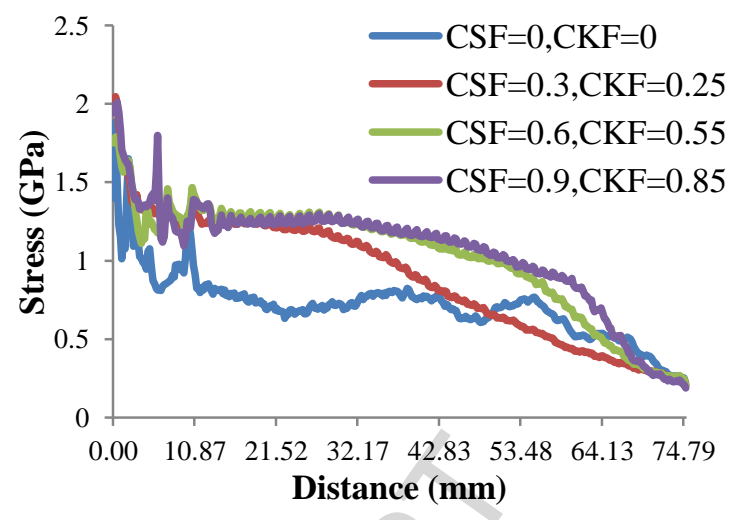

(d') weft yarn 5 at $12 \mu \mathrm{s}$

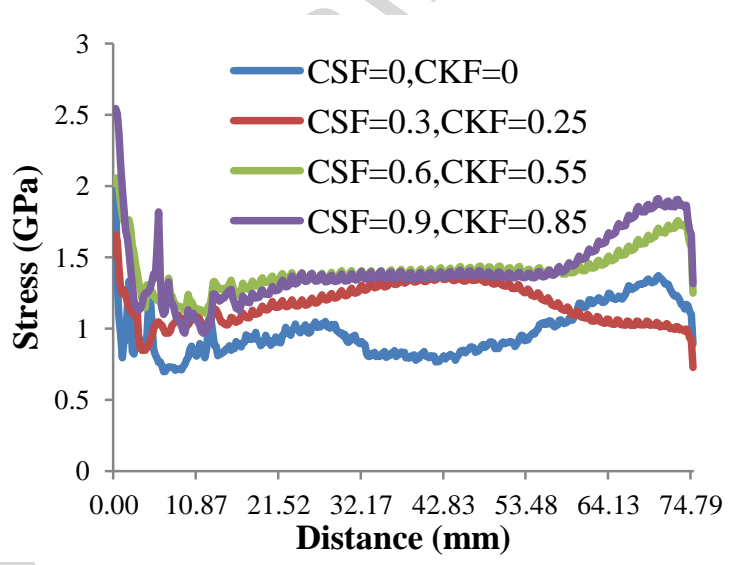

(e') weft yarn 5 at $15 \mu \mathrm{s}$

Figure 18 The von Mises stress distribution on the secondary yarns in DM 112 GPa case

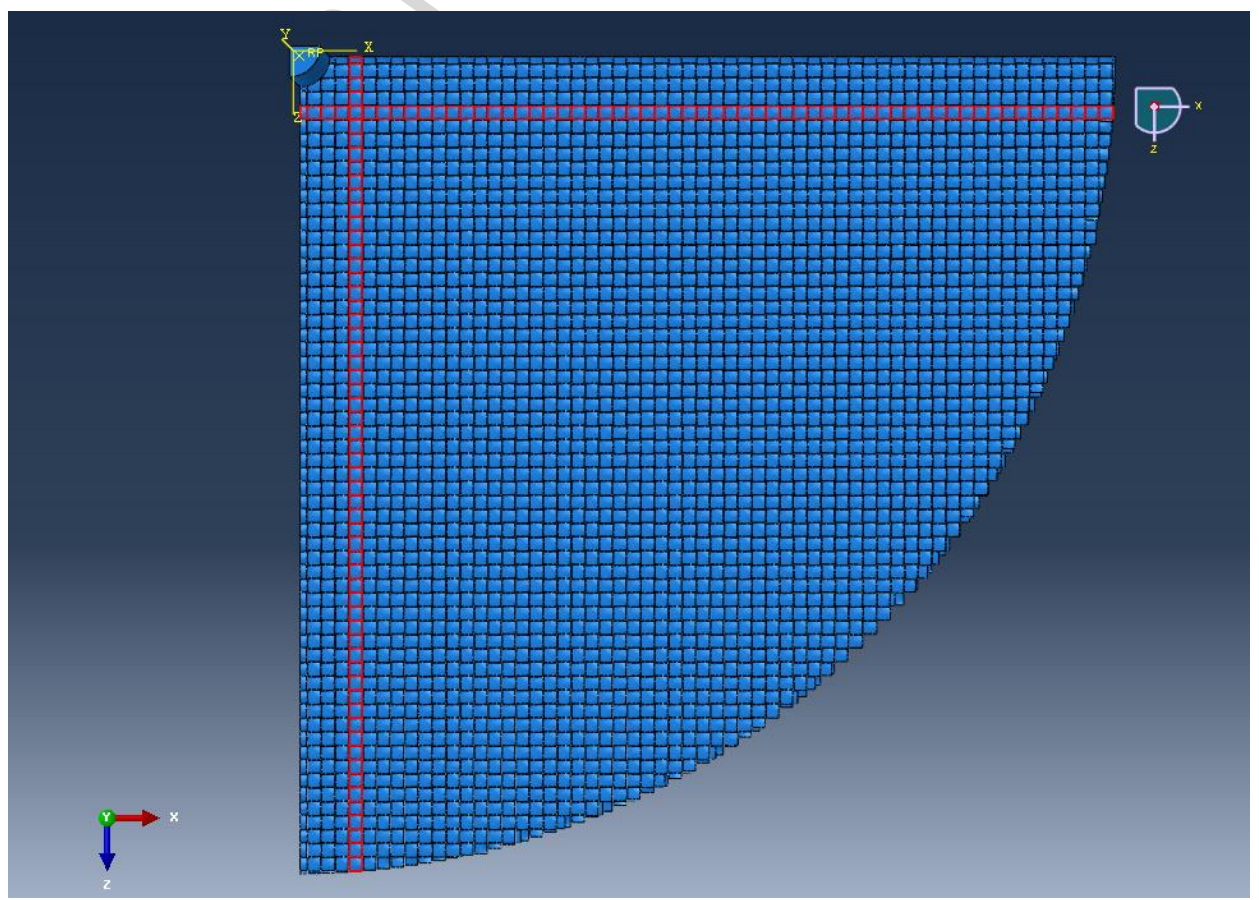


Figure 19 The position of the selected secondary yarns in red colour: warp yarn 5 along the $x$ axis and weft yarn 5 along the $z$ axis

\subsubsection{Involved area covered by secondary yarns}

The area that the transverse wave propagates to indicates the area that the impact energy can distribute onto. Most of these areas are occupied by secondary yarns. Figure 20 and 21 displays the profile of the area involved by the transverse wave from the FE simulation near the failure of the fabric in the two moduli cases. The elements with green colour are the involved area. Based on the profiles, the shape of the involved area slightly changes from triangle-like to more circular-like at higher levels of inter-yarn friction. The more circular-like shape indicates that the transverse wave spreads to more secondary yarns. The reason that the involved area becomes more circle-like may be that the higher inter-yarn friction can fix yarns more firmly at the crossover and thus make the whole structure more isotropic. More homogenous structure enables the transverse wave propagates more uniformly in all directions.

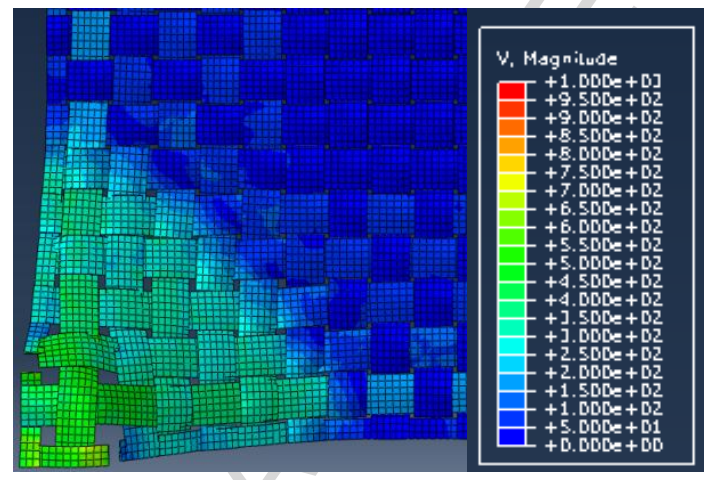

$\mathrm{CSF}=0, \mathrm{CKF}=0$

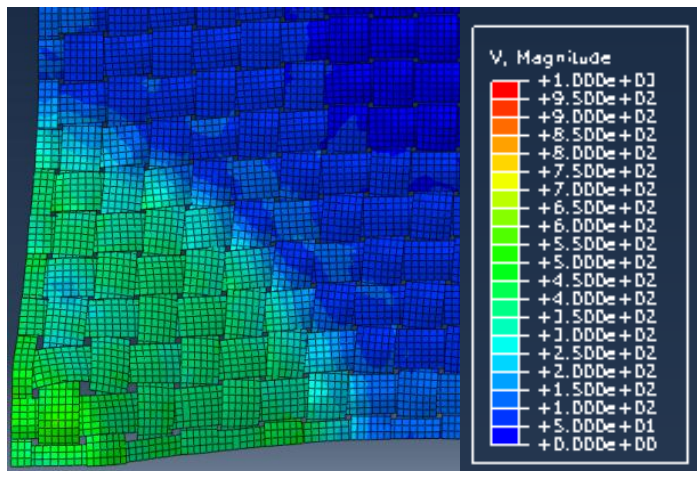

$\mathrm{CSF}=0.6, \mathrm{CKF}=0.55$

Figure 20 The profile of area involved in TM 72 Gpa case at $9 \mu \mathrm{s}$ 


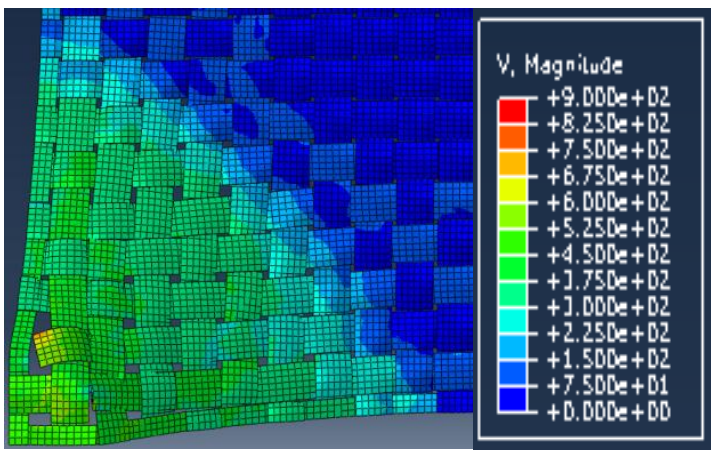

$\mathrm{CSF}=0, \mathrm{CKF}=0$

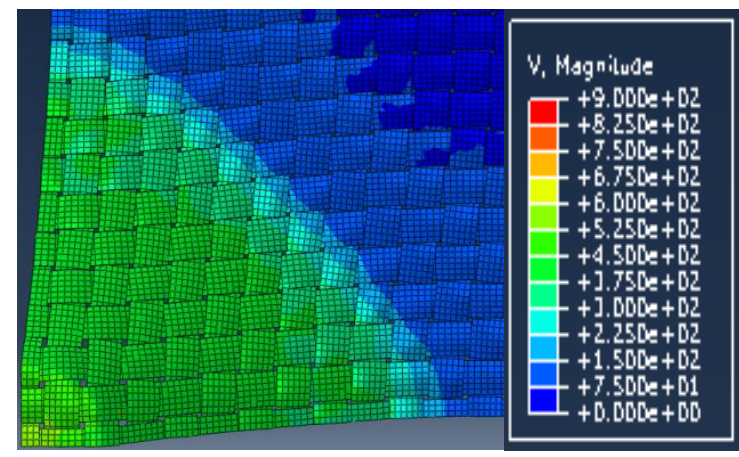

$\mathrm{CSF}=0.6, \mathrm{CKF}=0.55$

Figure21 The profile of area involved in DYM 112 GPa case at $12 \mu \mathrm{s}$

Figure 22 and 23 describe the changing process of the transverse wave in the two modulus cases every $3 \mu \mathrm{s}$ at the selected four frictional levels respectively. The horizontal and vertical axis indicates the involved area along the warp direction and the weft direction respectively. In these figures, the area enclosed by the two axes and the points is the involved area. At $3 \mu \mathrm{s}$, the involved areas at different frictional levels are almost the same. In the latter stage, the involved area is enlarged by a slight increase of inter-yarn friction (from zero friction to CSF of 0.30 and CKF of 0.25). Increasing inter-yarn friction will increase the involved area in the transverse wave propagation.

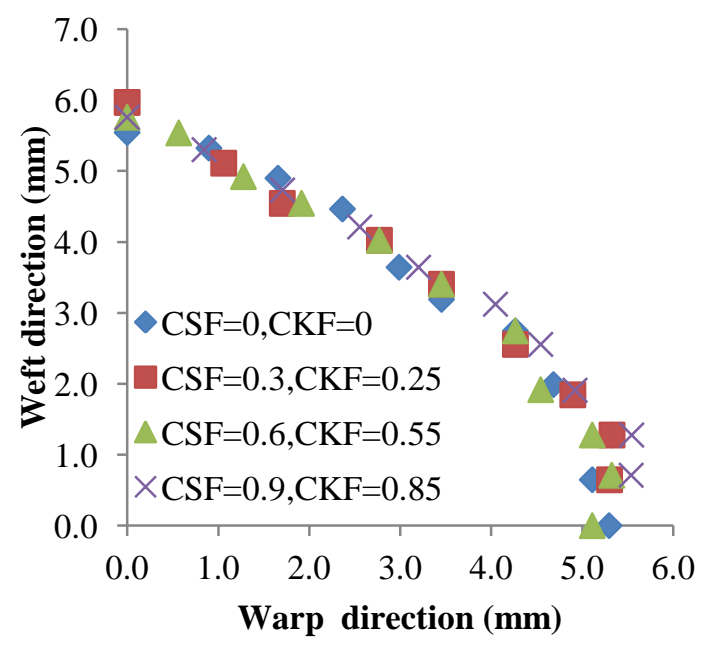

(a) $3 \mu \mathrm{s}$

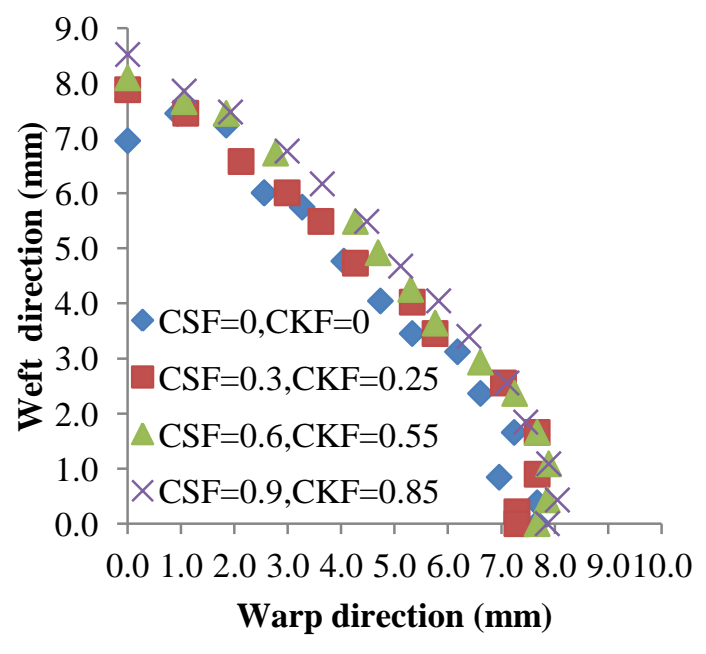

(b) $6 \mu \mathrm{s}$ 


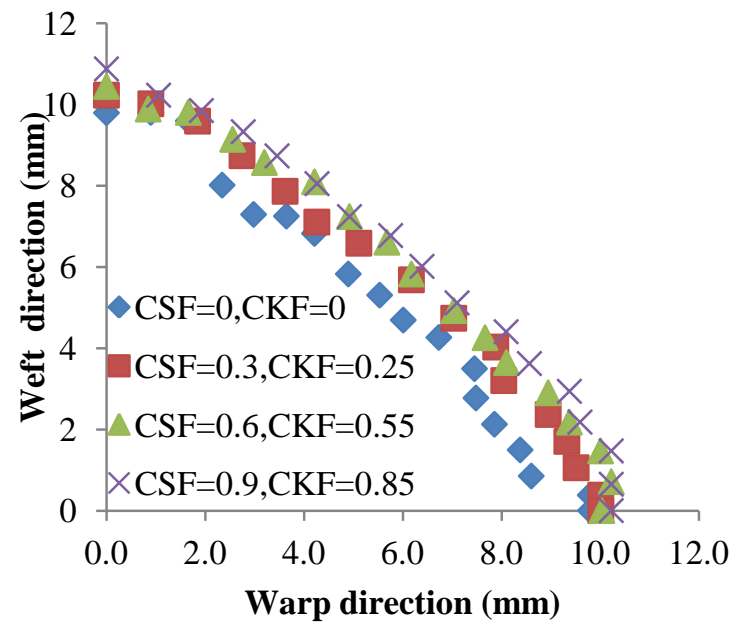

(c) $9 \mu \mathrm{s}$

Figure 22 The propagation of area covered by transverse wave in TM 72 GPa case

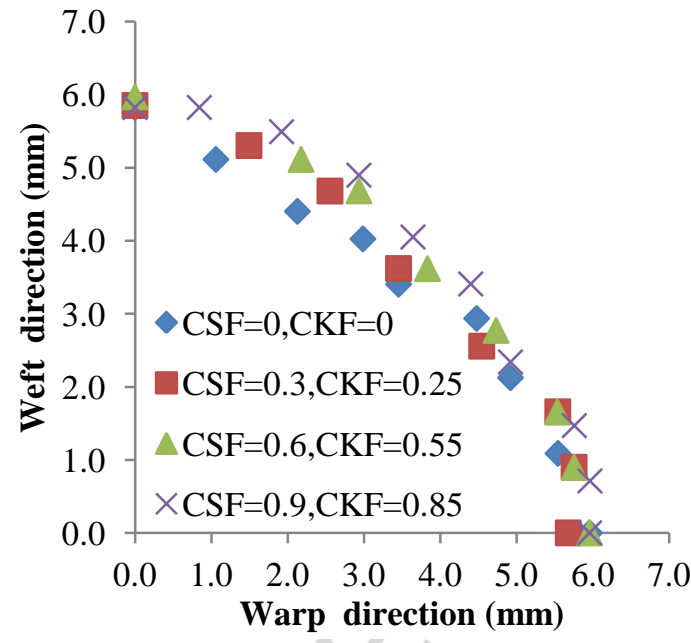

(a) $3 \mu \mathrm{s}$

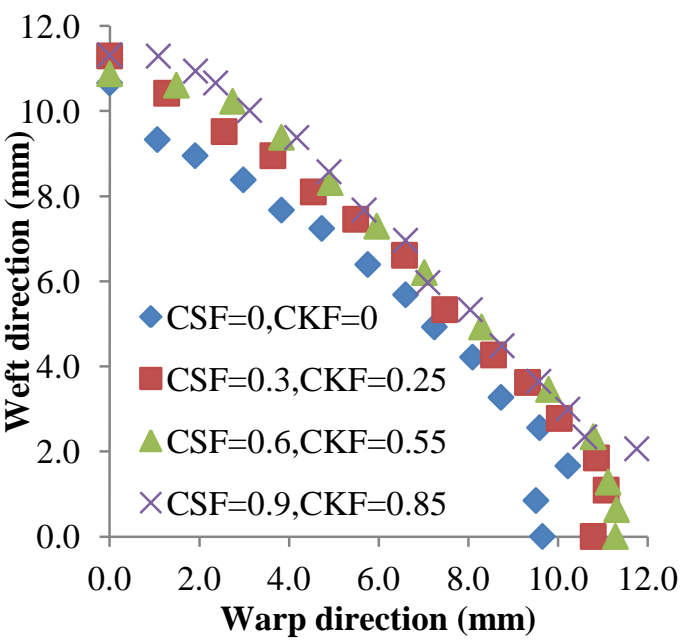

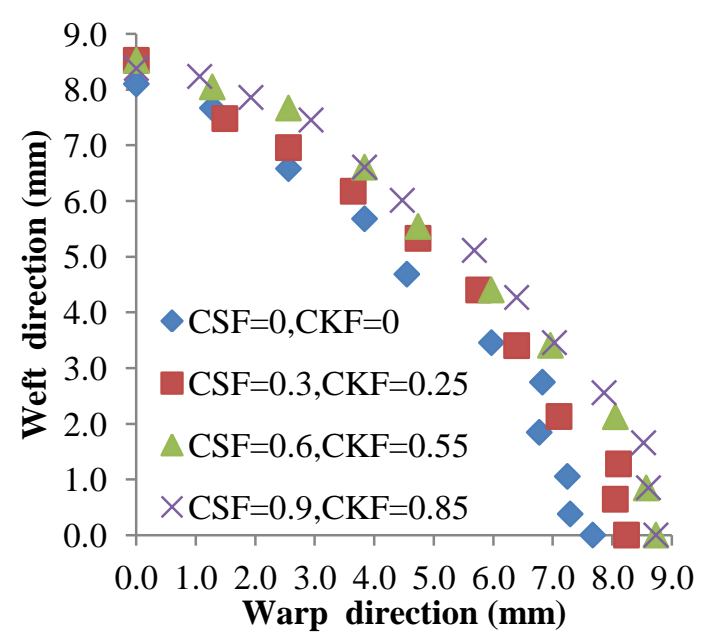

(b) $6 \mu \mathrm{s}$

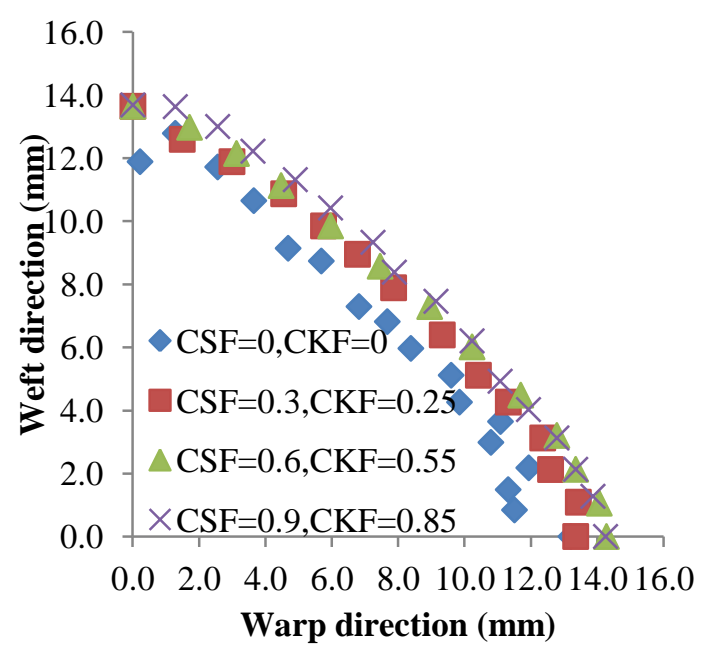



(a) $6 \mu \mathrm{s}$
(b) $9 \mu \mathrm{s}$

Figure 23 The propagation of area covered by transverse wave in DM 112 GPa case

\section{Discussions}

\subsection{The role of primary yarns and secondar y yarns}

Figure 24 shows the energy absorbed by the secondary yarns and the primary yarns occupied in the overall energy absorption with the increase of inter-yarn friction, respectively. Here the energy absorbed only includes the kinetic energy and strain energy. The frictional dissipated energy is not in calculation because it is infeasible to distinguish the frictional dissipated energy between primary yarns and secondary yarns in FE simulation. In the case of zero friction, the energy dissipated by the secondary yarns is smallest, accounting for $65.09 \%$ and $67.74 \%$ respectively for each fabric model. With the increase of inter-yarn friction, the secondary yarns dissipate more energy until the friction is beyond CSF of 0.60 and CKF of 0.55 in TM case and CSF of 0.40 and CKF of 0.35 in DM case. On the contrary, the amount of energy absorbed by the primary yarns as the function of inter-yarn friction presents an opposite trend. It is confirmed that secondary yarns can be engaged more in energy absorption to avoid the energy concentration on the primary yarns. From analyses of the stress distribution on secondary yarns in section 4.1 and the transverse wave propagation on secondary yarns in section 4.2, increasing inter-yarn friction can accelerate transverse wave propagation, enable secondary yarns to share more stress near the impact centre. These effects lead to more involvement of secondary yarns. The more involvement of secondary yarns indicates the load undertaken by primary yarns can be largely alleviated and efficiently transferred to secondary yarns. This is a beneficial action that can keep the primary yarns sustain longer and thus postpone the failure. The current finding confirmed the investigation form Roylance ${ }^{[29,30]}$ that increasing inter-yarn friction will increase the diversion part of the stress wave propagation, making the impact energy loaded on primary yarns transfer more to secondary yarns. Further increasing inter-yarn friction no longer affects the percentages of 
energy absorbed by secondary yarns and primary yarns, which indicates that an optimal inter-yarn friction exists for the most involvement of secondary yarns. That may be because the proportion of stress diversion at the crossover is not increased with the increase of inter-yarn friction beyond a certain level of inter-yarn friction.

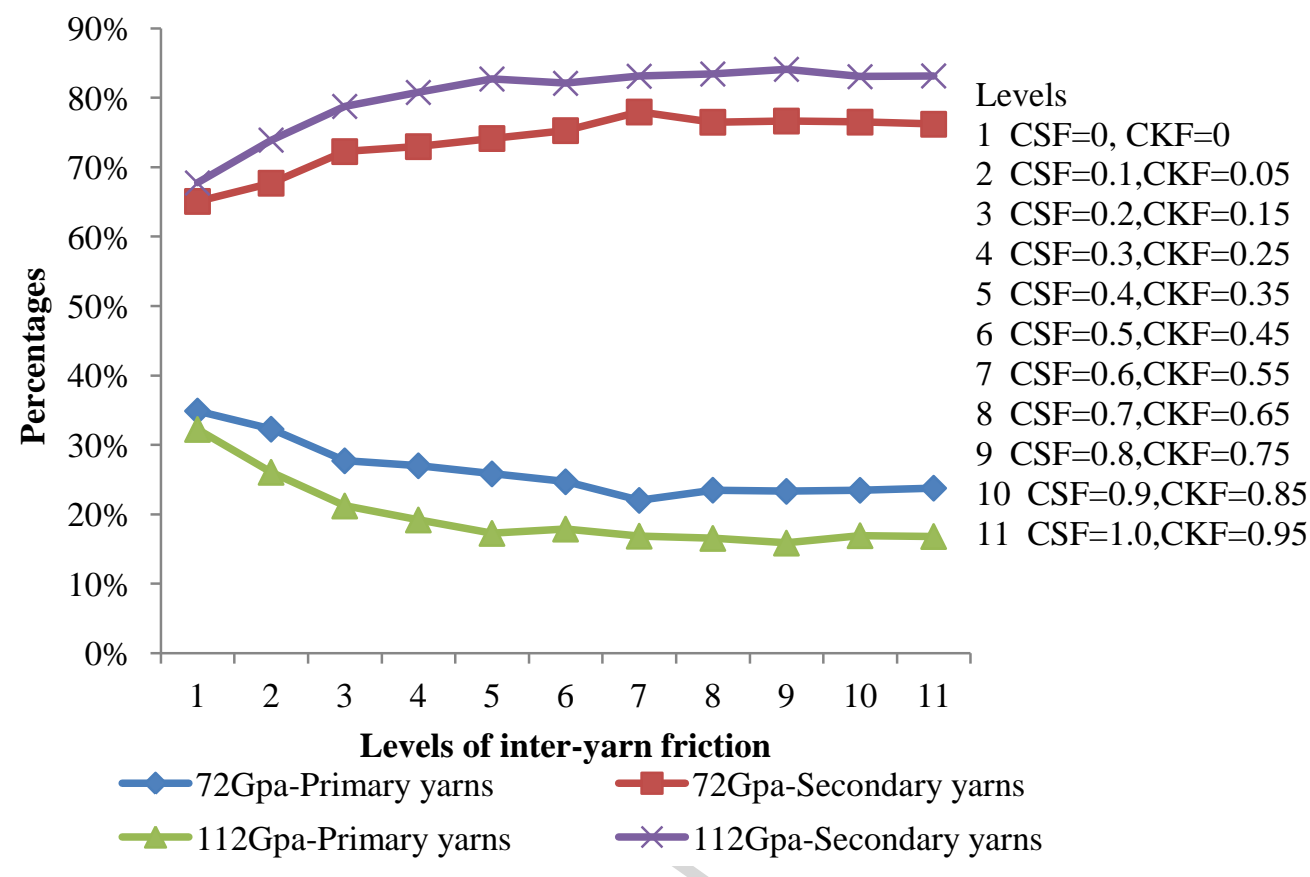

Figure 24 The proportion of energy dissipated on secondary yarns and primary yarns

\subsection{Failure mechanisam}

The effects of inter-yarn friction on the failure of a fabric can be understood from its effects on the failure time. The trend of the failure time for the fabrics with the increase of inter-yarn friction is shown in Figure 25. The failure time is the total time from the beginning of the impact to the fabric failure, which is the moment when the energy absorbed by the fabric keeps unchanged. In the TM $72 \mathrm{GPa}$, the time significantly shortens with the increase of the friction while it becomes a little longer as the CSF grows starting from 0.40 to 0.80 and CKF from 0.35 to 0.75 . When the friction is higher than CSF of 0.80 and CKF of 0.75 , the time becomes shorter once again. As DM $112 \mathrm{GPa}$ is concerned, the time firstly decreases as the inter-yarn friction increases by CSF of 0.20 and CKF of 0.15 and then gradually increases as the inter-yarn friction increases. When the inter-yarn friction reaches a much higher level of CSF of 0.80 and CKF of 0.75 , the time decreases 
again. The trend of the failure time with inter-yarn friction in the two cases is similar. The difference between the maximum failure time and minimum is around $2 \mu$ s in DM 112 GPa case whilst that for TM is approximate $6 \mu \mathrm{s}$.

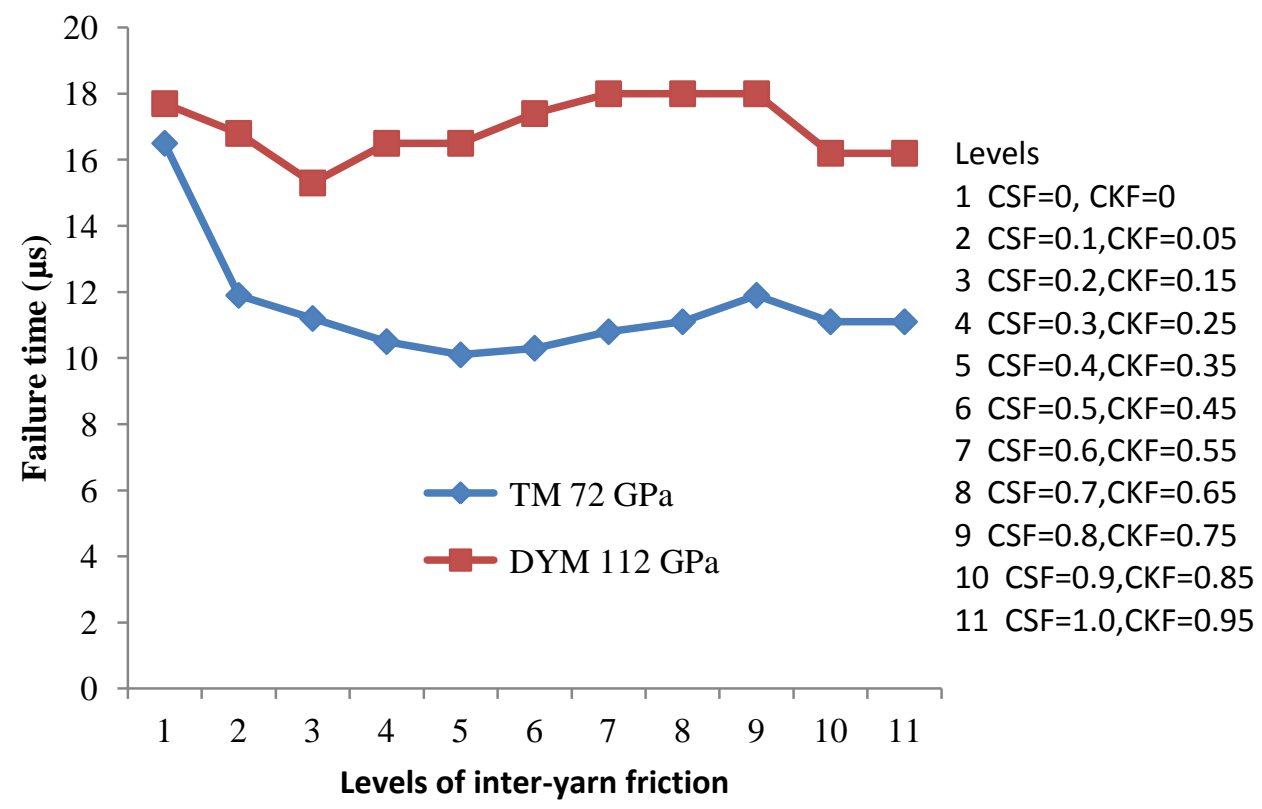

Figure 25 The trends of failure time of fabrics with the increase of the inter-yarn friction

The stress distribution on primary yarns, the structure stability at the impact centre and the involvement of secondary yarns would be responsible for the fabric failure. In this way, the understanding of the effects of inter-yarn friction on the failure mechanism will be explained with respect to the mentioned items. On one hand, increasing inter-yarn friction leads to more involvement of secondary yarns and hold the structure more stable. On the other hand, it produces more tensile and shear stress concentration on primary yarns. It is speculated that the failure of the fabric results from these positive and negative effects caused by increasing inter-yarn friction. Without inter-yarn friction, the fabric can transversely deform more to form a stress gradient and alleviate the yarn tension in the impact centre, resulting in the primary yarn surviving longer ${ }^{[31]}$. This can be evidenced by the largest transverse deflection ability of the fabric at zero inter-yarn friction. The effects of inter-yarn friction on the transverse deflection ability will be discussed in another paper. With the increase of inter-yarn friction ranging from $\operatorname{CSF}$ and $\operatorname{CKF}(0,0)$ to $(0.40,0.35)$ in 
TM case and from $\operatorname{CSF}$ and $\operatorname{CKF}(0,0)$ to $(0.20,0.15)$ in DM case, the failure time decreases. This may be because negative effects are much more pronounced, leading to the earlier fabric failure. However, beyond aforementioned levels, CSF and CKF $(0.40,0.35)$ for TM and CSF and CKF $(0.20,0.15)$ for DM, the failure time becomes a little longer. The explanation may be that the positive effects caused by increasing the inter-yarn friction cover the negative effects that it brings, and the transverse deflection ability no longer decreases, thus prolonging the fabric failure. As the frictional level surpasses CSF of 0.80 and CKF of 0.75 , the advantages caused by increasing inter-yarn friction diminish. In turn, the stress concentration becomes more dominant and results in the decline of the failure time again.

Thus, it can be concluded that in the whole applied inter-yarn friction range, the positive effects and negative effects compete with each other, leading to the fluctuation of the failure time. Comparing the TM fabric to DM fabric, the decrease in the failure time with an initial increase of inter-yarn friction is more significant. This is because the transverse deflection ability of the TM fabric is more significantly decreased, and this part will be further discussed in another paper. If the fabric has the comparative advantage in the transverse deflection ability, the fabric can transversely deflect more to sustain longer.

\section{Conclusions}

In this paper, two fabric models based on Twaron ${ }^{\circledR}$ and Dyneema ${ }^{\circledR}$ yarn properties were established for ballistic impact investigation. The effects of inter-yarn friction on the responses of primary yarns and secondary yarns in the two fabric models have been theoretically analysed by means of FE simulation. Numerical analyses show that inter-yarn friction would significantly affect the ballistic behaviours of yarns in fabrics. More inter-yarn friction leads to more impact energy shared by secondary yarns, thus alleviating the loads in primary yarns and prolonging the failure of primary yarns. In 
addition, at higher levels of inter-yarn friction, the structure of fabric can be kept much more stable, and less slip of primary yarns occurs and more resistance force to the projectile. However, much higher inter-yarn friction, somewhat beyond coefficient of static friction CSF of 0.8 and coefficient of kinetic friction (CKF) of 0.75 , is counterproductive because it will cause the stress to be concentrated more on primary yarns, resulting in earlier failure of a fabric. Those combined effects caused by inter-yarn friction make the failure time of the fabric fluctuate with the variation of inter-yarn friction.

\section{Acknowledgements}

The authors would like to thank Teijin for proving Twaron ${ }^{\circledR}$ yarns. The Ballistic Research Group at the University of Manchester are also gratefully appreciated. This paper is supported both by Henan provincial research program of functional and advanced technology (NO. 162300410058) and Open project program of Provincial Key Laboratory of Functional Textile Material of Henan

\section{Reference}

[1]Tran P, Ngo T, Yang E C, Mendis P and Humphries W, Effects of architecture on ballistic resistance of textile fabrics: Numerical study, International Journal of Damage Mechanics,2014 23(3):359-376

[2]Cheeseman BA and Bogetti TA (2003) Ballistic impact into fabric and compliant composite laminates. Composite Structures 61 (1):161-173

[3] Magno M, Ganghoffer JF, Postle R and Lallam A(2002) A mesoscopic wave model for textile materials in large deformations, Composite Structures 57 (2002) 367-371

[4] Boubaker BB, Haussy B and Ganghoffer JF(2007) Discrete woven structure model: yarn-on-yarn friction. Compes Rendus Mecanique 335 (2007) 150-158

[5]Duan Y, Keefe M, Bogetti T and Cheeseman B (2005) Modeling friction effects on the ballistic impact behavior of a single-ply high-strength fabric. International Journal of Impact Engineering 31 (8):996-1012 [6]Duan Y, Keefe M, Bogetti T, Cheeseman B and Powers B (2006) A numerical investigation of the influence of friction on energy absorption by a high-strength fabric subjected to ballistic impact. International Journal of Impact Engineering 32 (8):1299-1312

[7]Zeng X, Tan V and Shim V (2006) Modelling inter - yarn friction in woven fabric armour. International Journal for Numerical Methods in Engineering 66 (8):1309-1330

[8]Gogineni S, Gao X-L, David N and Zheng J (2012) Ballistic impact of Twaron CT709 ${ }^{\circledR}$ plain weave fabrics. Mechanics of Advanced Materials and Structures 19 (6):441-452

[9]Nilakantan G and Gillespie Jr JW (2012) Ballistic impact modeling of woven fabrics considering yarn strength, friction, projectile impact location, and fabric boundary condition effects. Composite Structures 94 (12):3624-3634 
[10]Zhou Y, Chen X and Wells G (2014) Influence of yarn gripping on the ballistic performance of woven fabrics from ultra-high molecular weight polyethylene fibre. Composites Part B: Engineering 62:198-204 [11]Sun D and Chen X (2012) Plasma modification of Kevlar fabrics for ballistic applications. Textile Research Journal 82 (18):1928-1934

[12]Ha-Minh C, Boussu F, Kanit T, Crépin D and Imad A (2012) Effect of frictions on the ballistic performance of a 3D warp interlock fabric: numerical analysis. Applied Composite Materials 19:333-347 [13]Rao M, Duan Y, Keefe M, Powers B and Bogetti T (2009) Modeling the effects of yarn material properties and friction on the ballistic impact of a plain-weave fabric. Composite Structures 89 (4):556-566 [14]Parsons EM, King MJ and Socrate S (2013) Modeling yarn slip in woven fabric at the continuum level: Simulations of ballistic impact. Journal of the Mechanics and Physics of Solids 61 (1):265-292

[15]Briscoe B and Motamedi F (1992) The ballistic impact characteristics of aramid fabrics: the influence of interface friction. Wear 158 (1):229-247

[16]Hearle J, Leech C, Adeyefa A and Cork C (1981) Ballistic impact resistance of multi-layer textile fabrics. University of Manchester INST of Science and Technology( United Kingdom) DEPT of Textile Technology, Manchester

[17]Sun D, Chen X and Wells G (2014) Engineering and analysis of gripping fabrics for improved ballistic performance. Journal of Composite Materials:1355-1364

[18]Sun D, Chen X and Mrango M (2013) Investigating ballistic impact on fabric targets with gripping yarns. Fibers and Polymers 14 (7):1184-1189

[19]Zhou Y, Chen X and Wells G (2014) Influence of yarn gripping on the ballistic performance of woven fabrics from ultra-high molecular weight polyethylene fibre. Composites Part B: Engineering 62:198-204

[20] Min S , ChuY and Chen X(2016), Numerical study on mechanisms of angle-plied panels for ballistic protection, Materials and Design 90896 - 905

[21]Goda I, Assidi M and Ganghoffer JF(2013) Equivalent mechanical properties of textile monolayers from discrete asymptotic homogenization, Journal of the Mechanics and Physics of Solids, 61(12) 2537-2565

[22] Ganghoffer J F, Rahali Y, Goda I(2016) Numerical identification of classical and nonclassical moduli of 3D woven textiles and analysis of scale effects, Composite Structures 135,122-139

[23]Talebi H, Wong S and Hamouda A (2009) Finite element evaluation of projectile nose angle effects in ballistic perforation of high strength fabric. Composite Structures 87 (4):314-320

[24]Bouwmeester JGH, Marissen R and Bergsma OK Carbon/dyneeam interlaminar hybrids: new strategy to increae impact resistance or decrease mass of carbon fibre composites. In: 26th international congress of the aeronautical sciences, Anchorage, Alaska, USA, 2008. pp 3851-3856

[25]Lysenko AA, Lysenko VA, Astashkina OV and Gladunova OI (2011) Resource-conserving carbon fibre technologyies. Fibre Chemistry 42 (5):278-286

[26]Technical brochure: Dyneema ${ }^{\circledR}$ in marine and industrial applications. www.dyneema.com.

[27]Zhou Y (2013) Development of lightweight soft body armour for ballistic protection. The University of Manchester, Manchester

[28]Duan Y, Keefe M, Bogetti T and Powers B (2006) Finite element modeling of transverse impact on a ballistic fabric. International Journal of Mechanical Sciences 48 (1):33-43

[29]Roylance D (1973) Wave propagation in a viscoelastic fiber subjected to transverse impact. Journal of Applied Mechanics 40 (1):143-148

[30]Roylance D (1980) Stress wave propagation in fibres: effect of crossovers. Fibre Science and 
Technology 13 (5):385-395

[31]Parsons EM, King MJ and Socrate S (2013) Modeling yarn slip in woven fabric at the continuum level: Simulations of ballistic impact. Journal of the Mechanics and Physics of Solids 61 (1):265-292 


\section{Highlights}

(1) Higher inter-yarn friction results in less slippage of primary yarns at impact centre.

(2) Higher inter-yarn friction make more involvement of the secondary yarns join in loading the impact energy

(3) The inter-yarn friction beyond coefficient of static friction (CSF) of 0.8 and coefficient of kinetic friction $(\mathrm{CKF})$ of 0.75 would cause stress concentration on primary yarns leading to earlier fabric failure. 